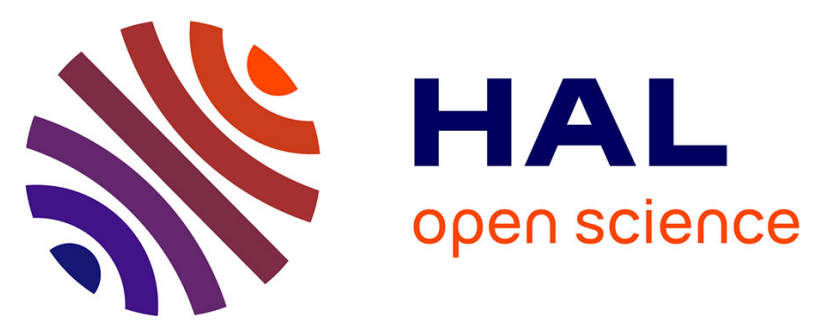

\title{
Implication of oxidant activation on olefin epoxidation catalysed by Molybdenum catalysts with aroylhydrazonato ligands: Experimental and theoretical studies
}

\author{
Arijeta Bafti, Marta Razum, Edi Topić, Dominique Agustin, Jana Pisk, \\ Višnja Vrdoljak, ] A Bafti, Iut a P Sabatier
}

\section{To cite this version:}

Arijeta Bafti, Marta Razum, Edi Topić, Dominique Agustin, Jana Pisk, et al.. Implication of oxidant activation on olefin epoxidation catalysed by Molybdenum catalysts with aroylhydrazonato ligands: Experimental and theoretical studies. Molecular Catalysis, 2021, 512, pp.111764. 10.1016/j.mcat.2021.111764 . hal-03356884

\section{HAL Id: hal-03356884 https://hal.science/hal-03356884}

Submitted on 28 Sep 2021

HAL is a multi-disciplinary open access archive for the deposit and dissemination of scientific research documents, whether they are published or not. The documents may come from teaching and research institutions in France or abroad, or from public or private research centers.
L'archive ouverte pluridisciplinaire HAL, est destinée au dépôt et à la diffusion de documents scientifiques de niveau recherche, publiés ou non, émanant des établissements d'enseignement et de recherche français ou étrangers, des laboratoires publics ou privés. 


\section{Implication of oxidant activation on olefin epoxidation catalysed by Molybdenum catalysts with aroylhydrazonato ligands: Experimental and theoretical studies}

Arijeta Bafti, ${ }^{\dagger[a, b]}$ Marta Razum, ${ }^{\dagger[a, c]}$ Edi Topić, ${ }^{[a]}$ Dominique Agustin, ${ }^{*}{ }^{[d, e]}$ Jana Pisk, ${ }^{*[a] ~ V i s ̌ n j a ~}$ Vrdoljak[a]

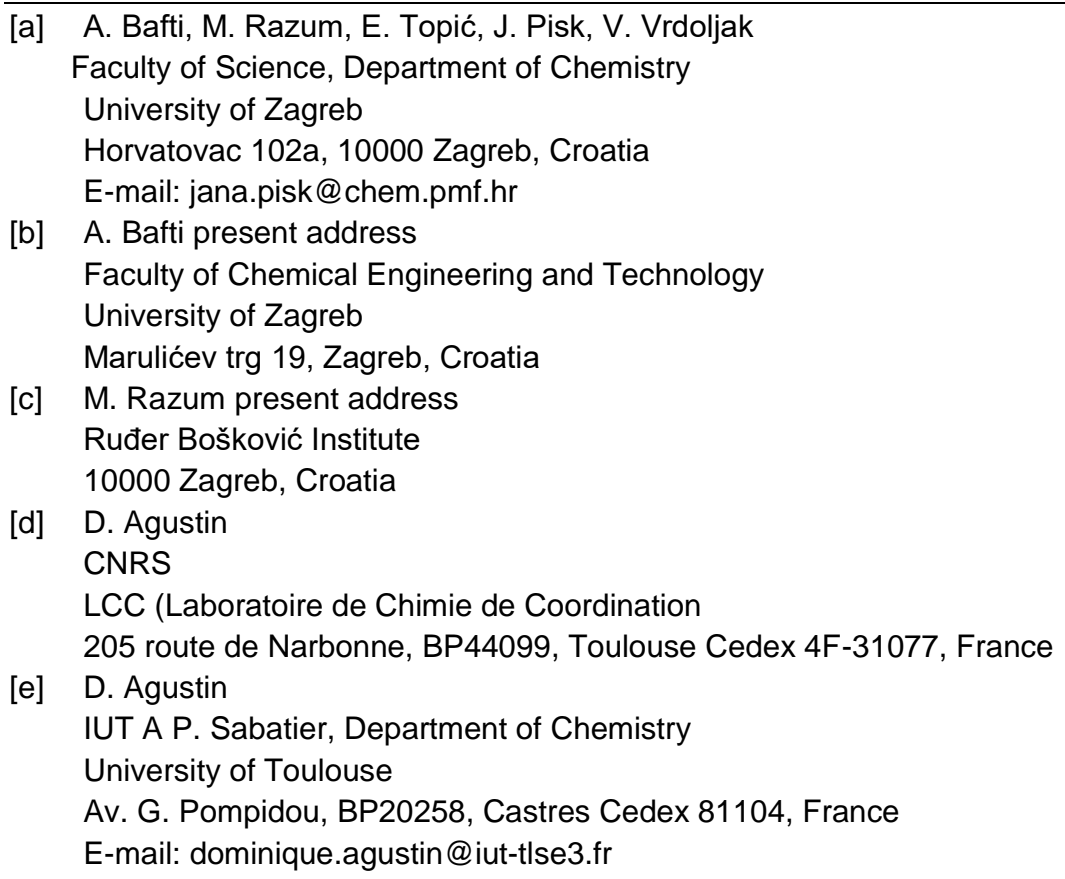

$\dagger \quad$ equally contributed authors

CRediT author statement: Arijeta Bafti: Data curation, Formal analysis, Marta Razum: Data curation; Formal analysis, Edi Topić: Data curation; Formal analysis; Writing - review \& editing, Visualization), Dominique Agustin: Conceptualization; Investigation; Methodology; Resources; Software; Supervision; Validation; Visualization; Writing - original draft; Writing review \& editing, Jana Pisk: Conceptualization; Data curation; Investigation; Methodology; Resources; Supervision; Validation; Visualization; Writing; Writing - review \& editing; Višnja Vrdoljak: Conceptualization; Funding acquisition; Methodology; Project administration; Resources; Writing - review \& editing. 


\section{Highlights:}

- Dinuclear and mononuclear molybdenum(VI) complexes with aroylhydrazonato ligands were tested as catalysts for cyclooctene and oct-1-ene epoxidation.

- TBHP in decane provided outstanding results in terms of cyclooctene epoxidation: TOF $_{2.5 \mathrm{~min}}>9000$ with $0.25 \mathrm{~mol} \%$ [Mo] loading.

- DFT calculations confirmed the relationship between the ligand nature and reactivity with TBHP and $\mathrm{H}_{2} \mathrm{O}_{2}$ as oxidant agents. 


\section{Abstract:}

Dinuclear and mononuclear molybdenum( $\mathrm{VI})$ complexes with aroylhydrazonato ligands were studied as catalysts for cyclooctene and oct-1-ene epoxidation. Different isomers of the $\mathrm{OH}$ and $\mathrm{NH}_{2}$ functionalised aroylhydrazones led to four specific $\left[\mathrm{MoO}_{2} \mathrm{~L}\right]$ units showing different catalytic activity. Three oxidants have been investigated: tert-butylhydroperoxide (TBHP) in water or in decane, and hydrogen peroxide $\left(\mathrm{H}_{2} \mathrm{O}_{2}\right)$. Catalytic processes with TBHP in decane provided outstanding results in the case of cyclooctene epoxidation: TOF $2.5 \mathrm{~min}>9000$ with $0.25 \mathrm{~mol} \%$ [Mo] loading. DFT calculations confirmed the relationship between the ligand nature and reactivity with TBHP and $\mathrm{H}_{2} \mathrm{O}_{2}$ as oxidant agents. In the case of TBHP as oxidant, calculations considered the solvent in which the oxidant is delivered to the olefin. A plausible mechanism with $\mathrm{H}_{2} \mathrm{O}_{2}$ has been proposed after considering various pathways.

Keywords: Molybdenum $•$ aroylhydrazones $\cdot$ epoxidation $・$ DFT $\bullet$ peroxides

\section{Introduction}

Molybdenum-catalysed epoxidation is the core business for propylene oxide production, as well as widely applied for laboratory researched alkyl olefin (ep)oxidation. Generally, processes using organic peroxides and peracids are traditional and common in the industry, causing pollution and environmental issues. ${ }^{[1,2]}$ However, milder oxidants as $\mathrm{O}_{2}, \mathrm{H}_{2} \mathrm{O}_{2}$, or alkyl hydroperoxides (e.g. tert-butylhydroperoxide (TBHP)) provide a greener alternative for process improvement (highly efficient catalysts, better green metrics parameters, as atom economy and $E$-factor) ${ }^{[3]}$ Commercially available $\left[\mathrm{MoO}_{2}(\mathrm{acac})_{2}\right]$ has been used and proved to be one of the best molecular catalysts for olefin epoxidation with the use of TBHP in decane, in presence of additional organic solvents. ${ }^{[4,5]}$ Furthermore, mono-, di- or poly-nuclear Mo complexes with pyridoxal- or salicylaldehyde-based ligands, as ONS or ONO coordinating ligands, justified excellent catalytic performance following green experimental policies. ${ }^{[6-9]}$ Recently, dinuclear aminobenzhydrazonato $\mathrm{Mo}(\mathrm{VI})$ complexes were proved to be very efficient epoxidation catalysts. ${ }^{[8]}$

Consequently, we have continued further investigation in the quest for a more active catalyst towards understanding the possible epoxidation mechanism. Combination of 2- or 4aminobenzhydrazide and 2,3- or 2,4-dihydrosalicylaldehyde coordinated to Mo centre sound as promising active species. For that reason, here we report simple Mo catalytic systems based on aroylhydrazones (Scheme 1), applicable for epoxide synthesis, respecting the principles of green chemistry. Different oxidizing agents, $\mathrm{H}_{2} \mathrm{O}_{2}$ and TBHP in water and decane, were tested on cyclooctene and oct-1-ene as model substrates. It should be mentioned that oct-1-ene has not been extensively investigated with molecular Mo catalysts, ${ }^{[10,11]}$ and most of the reported researches need the addition of organic solvents for better catalytic results. ${ }^{[12,13]}$ 
Despite industrial relevance and historical background, the mechanism for $\mathrm{Mo}(\mathrm{VI})$ catalysed olefin epoxidation has been extensively debated. ${ }^{[14-18]}$ It is accepted that catalyst activates the oxidant molecule to favour the oxygen atom transfer (OAT) to the substrate. However, OAT details are still the issue of discussions. Herein, the experimental part, driven by DFT calculations, considered the reaction medium, i.e. the solvent used for oxidant delivery. Moreover, this mechanistic study highlights the underexplored oxidant $\mathrm{H}_{2} \mathrm{O}_{2}$, through several pathways' consideration, and the importance of the ligand was elucidated.

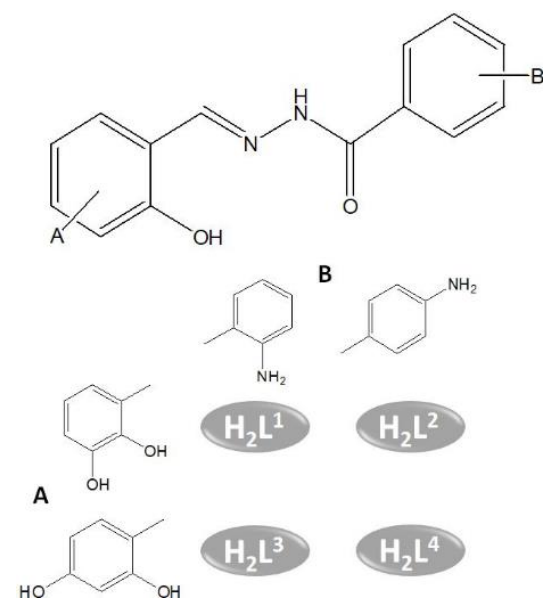

Scheme 1. Aroylhydrazones used for the preparation of the Mo catalytic systems. ${ }^{[19]}$

\section{Results and Discussion}

\subsection{Preparation, spectral characterization and thermal behaviour}

The reaction of equimolar amounts of $\left[\mathrm{MoO}_{2}(\mathrm{acac})_{2}\right]$ and corresponding aminobenzhydrazone ligand $\mathrm{H}_{2} \mathrm{~L}^{1-4}$ (Scheme 1), in methanol or acetonitrile, yielded $\mathrm{Mo}(\mathrm{VI})$ complexes (Scheme 2, Scheme S1). Dinuclear complexes, $\left[\mathrm{MoO}_{2}\left(\mathrm{~L}^{1}\right)\right]_{2} \quad(\mathbf{1}), \quad\left[\mathrm{MoO}_{2}\left(\mathrm{~L}^{2}\right)\right] 2 \cdot \mathrm{MeCN} \quad(\mathbf{2} \cdot \mathrm{MeCN})$, $\left[\mathrm{MoO}_{2}\left(\mathrm{~L}^{3}\right)\right]_{2} \cdot \mathrm{MeCN}(3 \cdot \mathrm{MeCN})$, and $\left[\mathrm{MoO}_{2}\left(\mathrm{~L}^{4}\right)\right]_{2}(4)$, were obtained from acetonitrile, while mononuclear complexes, $\left[\mathrm{MoO}_{2}\left(\mathrm{~L}^{1}\right)(\mathrm{MeOH})\right](\mathbf{1 a}),\left[\mathrm{MoO}_{2}\left(\mathrm{~L}^{2}\right)(\mathrm{MeOH})\right](\mathbf{2 a}),\left[\mathrm{MoO}_{2}\left(\mathrm{~L}^{3}\right)(\mathrm{MeOH})\right]$ (3a), and $\left[\mathrm{MoO}_{2}\left(\mathrm{~L}^{4}\right)(\mathrm{MeOH})\right](\mathbf{4 a})$, were obtained from methanol. The crystallization process for mononuclear complexes $\mathbf{1 a}$ and $\mathbf{4 a}$, respectively, lasted for more than a month and the products were obtained in very low yield relative to the other obtained complexes $(13 \%$ and $19 \%$, respectively). Furthermore, if the reaction mixture of $\left[\mathrm{MoO}_{2}(\mathrm{acac})_{2}\right]$ and $\mathrm{H}_{2} \mathrm{~L}^{3}$ was fairly concentrated, the dimerization occurred differently and obtained complex was not identified as 3.MeCN, but as the dinuclear one $3^{\star} \cdot \mathrm{MeCN}$. The analogous reaction with the ligand $\mathrm{H}_{2} \mathrm{~L}^{4}$ provided the only product 4. 


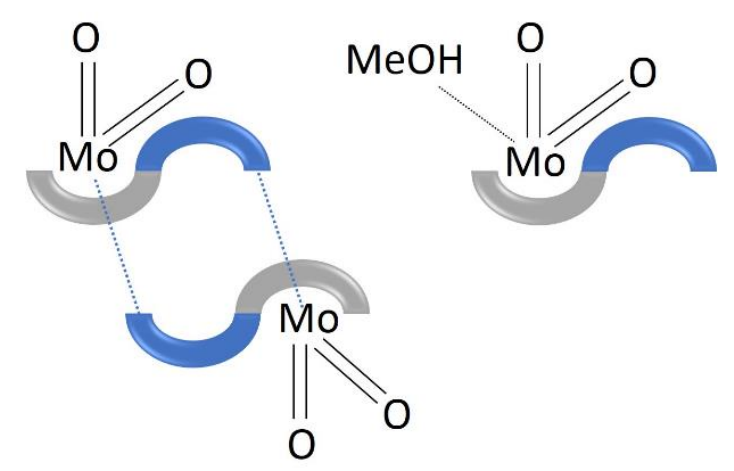

Scheme 2. Mo(VI) dinuclear (left) and mononuclear (right) molecular catalysts. Grey-blue block arcs present aroylhydrazone, where the grey arch is aldehyde part and the blue arc is the hydrazide part. The dotted blue line presents dimerization through Mo centre of one unit and $\mathrm{NH}_{2}$ from the neighbouring complex molecule.

Crystallization of the mononuclear complexes $\mathbf{1 a}$ and $\mathbf{2} \mathbf{a}, \mathbf{3} \mathbf{a}$, and $\mathbf{4 a}$ in acetonitrile resulted in the formation of dinuclear complexes 1, 2-MeCN, 3-MeCN, and 4. Furthermore, by exposing complex 2 and $\mathbf{3}$ (obtained by drying solvated compounds) to acetonitrile vapours, their solvated counterparts, $2 \cdot \mathrm{MeCN}$ and $3 \cdot \mathrm{MeCN}$, could be efficiently recycled. This feature renders 2 and 3 as (efficient) acetonitrile adsorbents bearing that acetonitrile in the air is known to be poisonous at low concentrations. ${ }^{[20]}$ While mononuclear complexes were obtained by the direct reaction in methanol, the polynuclear compound $4^{\star \star}$ was surprisingly obtained by solvothermal synthetic procedure.

In all complexes, bands around $3400 \mathrm{~cm}^{-1}$ are assigned to $\mathrm{O}-\mathrm{H}$ stretching and around 3100 $-3200 \mathrm{~cm}^{-1}$ to $\mathrm{N}-\mathrm{H}$ bond vibrations. Also, bands around $1600 \mathrm{~cm}^{-1}$ are characteristic of $\mathrm{C}=\mathrm{N}$ imine bond stretching. $\mathrm{C}-\mathrm{O}_{\text {phenolic }}$ absorption bands are in the range of $1240-1263 \mathrm{~cm}^{-1}$. The absence of vibrations around $1650 \mathrm{~cm}^{-1}$, characteristic of $\mathrm{C}=\mathrm{O}$ group, indicates tautomerization of ligands and coordination through the deprotonated oxygen atom (Scheme 1). Furthermore, strong vibrations in the range $910-940 \mathrm{~cm}^{-1}$ are characteristic for $\left\{\mathrm{MoO}_{2}\right\}^{2+}$ core. For dinuclear structures absorption bands in the range of $870-900 \mathrm{~cm}^{-1}$ confirm that the coordination sphere of molybdenum is completed by the nitrogen atom from the neighbouring complex molecule, as already noticed for similar compounds. ${ }^{[8,9]}$ For the complex $\mathbf{2} \cdot \mathbf{M e C N}$, absorption maximum characteristic for MeCN was not noticed in the IR spectrum, while the band at $2340 \mathrm{~cm}^{-1}$ was present in the spectrum of $\mathbf{3} \cdot \mathbf{M e C N}$. The presence of the MeCN in $\mathbf{2} \cdot \mathbf{M e C N}$ was later confirmed by TG analysis. The spectrum of $3^{*} \cdot \mathrm{MeCN}$ showed a strong stretching frequency at $870 \mathrm{~cm}^{-1}$, characteristic of the $\mathrm{Mo}_{2} \mathrm{O}_{2 b}$ core presence, implying dimerization through terminal $\mathrm{O}$ atom (Fig. S1). ${ }^{21]}$ That is supported by the absence of a broad band in that region characteristic for the interaction $\mathrm{Mo}=\mathrm{O}_{\mathrm{t}} \cdots \mathrm{Mo}$ and polymerization. In the mononuclear structures 1a-4a absorption band at $1010-1020 \mathrm{~cm}^{-1}$ indicates the presence of coordinated $\mathrm{MeOH}$.

The NMR interpretation for the compounds 1-4 is presented in Scheme S2, Table S1, S2, respectively. The NMR spectroscopy confirmed that the ONO coordination mode of the ligands was retained in solution. The spectra of the mononuclear and corresponding dinuclear complexes were found to be quite similar. This suggested that dmso- $d 6$ was coordinated to the sixth coordination site in both cases. The spectra of 1a-4a contained additional signals for free 
$\mathrm{MeOH}$. Coordination of hydrazones to Mo produced appreciable chemical shifts more pronounced for carbon atoms than for protons. Deshielding effects of $6.22-5.38 \mathrm{ppm}$ and 5.76 - $3.32 \mathrm{ppm}$ were observed at $\mathrm{C} 1$ and $\mathrm{C} 4$, respectively (Tables S1 and S2). The interacting site C12 was only slightly deshielded relative to $\mathrm{H}_{2} \mathrm{~L}^{1-4}$.

All complexes were analysed by thermogravimetry under the oxygen atmosphere and in a temperature range from 25 to $600^{\circ} \mathrm{C}$. As a final product of thermal decomposition, $\mathrm{MoO}_{3}$ was formed as confirmed by the powder X-ray diffraction method. The first weight loss, which occured in the range of $35-105^{\circ} \mathrm{C}$, of the dinuclear complex 2.MeCN and $150-200{ }^{\circ} \mathrm{C}$ for 3.MeCN was related to the loss of the acetonitrile molecule. Further heating of complexes 2 and 3 results in a significant weight loss in the range of $250-480^{\circ} \mathrm{C}$ due to complex decomposition. In the case of dinuclear complexes $\mathbf{1}$ and $\mathbf{4}$, there was no crystalline solvent present in the crystal structure, and mass loss in the range $300-490^{\circ} \mathrm{C}$ is due to complex decomposition. Complexes $3^{\star}$ and $4^{\star *}$ decomposed in the range $301-469^{\circ} \mathrm{C}$ and $322-489^{\circ} \mathrm{C}$, respectively. TG analyses of the mononuclear complexes $1 \mathrm{a}-4 \mathrm{a}$ showed two-step processes: desolvation and complex decomposition. In the first step, weight loss of around $7.5 \%$ in the range of $140-$ $157^{\circ} \mathrm{C}$ for $\mathbf{1 a}, 107-150^{\circ} \mathrm{C}$ for $\mathbf{2 a} \cdot \mathbf{M e O H}, 123-167^{\circ} \mathrm{C}$ for $3 \mathbf{a}$, and $90-145^{\circ} \mathrm{C}$ for $4 \mathbf{a}$ was related to the loss of methanol molecule(s). Desolvation of $\mathbf{1 a}-4 \mathbf{a}$ was followed by ligand decomposition and significant weight loss in the range of about $250-450{ }^{\circ} \mathrm{C}$.

\subsection{Crystallographic study}

Molecular and crystal structures of the dinuclear complex $3 \cdot \mathbf{M e C N}$, mononuclear complexes $3 \mathbf{a}$ and $2 \mathrm{a} \cdot \mathrm{MeOH}$, and the polynuclear complex $\mathbf{4}^{\star \star}$ were determined via single-crystal X-ray diffraction experiments (Fig. 1). A detailed description of experimental data, geometrical parameters, and description of crystal packing can be found in Figures S2-S5, Tables S3-S7. In all analysed cases, cis- $\left\{\mathrm{MoO}_{2}\right\}^{2+}$ core is coordinated by a deprotonated 2-hydroxyl group of aldehyde part, azomethine nitrogen, and oxygen atom from hydrazide functional group, forming an ONO coordinating pocket with the ligand in a dianionic hydrazidato form. The sixth coordination place is occupied differently according to the nature of the complex: while in mononuclear complexes sixth coordination place is occupied with a methanol molecule, the absence of good donor groups in dinuclear or polynuclear complexes yields coordination of auxiliary functional groups of the ligand. This behaviour is well established in previous works. ${ }^{[8,9,22]}$

Regarding the geometry of the ligand and the coordination sites, all analysed complexes ultimately possess the same tautomeric form and overall shape. Bond lengths (Table S3) suggest enol-imino form in the hydrazide functional group, as well as enolate form of chelating hydroxyaryl unit. The ligand molecules themselves are somewhat distorted regarding their planarity, with angles between aromatic planes ranging from $2.05^{\circ}$ to $13.68^{\circ}$ in analysed complexes, which agrees with the geometry of similar systems $\left(11^{\circ} \pm 9^{\circ}\right)$. Moreover, the deviation of the molybdenum atom from ONO plane ranges from 0.238 to $0.350 \AA$, compared to the average value of $0.30 \pm 0.04 \AA$ from previously known crystal structures (Table S5). 


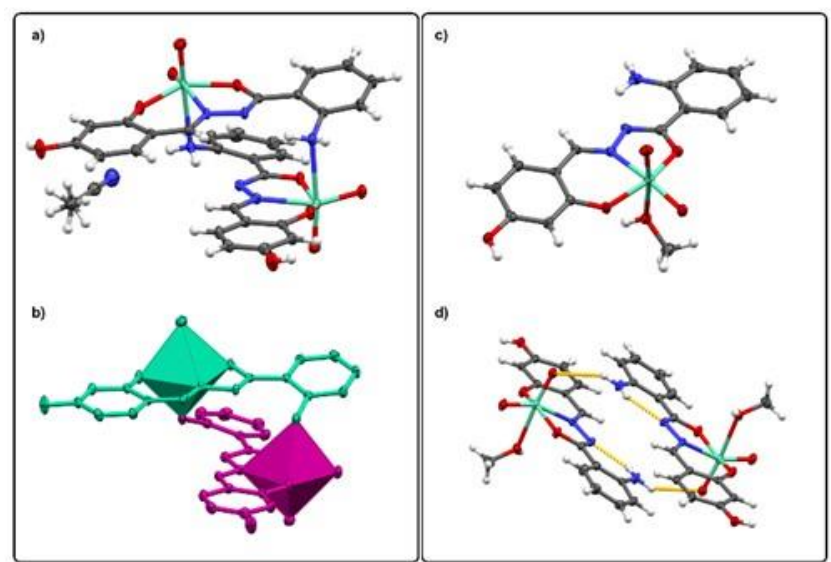

Fig. 1. a) Molecular structure of dinuclear complex 3.MeCN, with b) two monomeric units, in different colours, connected through the coordination of the amino group. On the other side, c) monomeric complex $3 a$ achieves d) supramolecular dimerization via hydrogen bond interaction (yellow line) of the amino group with $\left\{\mathrm{MoO}_{2}\right\}^{2+}$ core.

It is interesting to note the interplay of covalent and non-covalent bonding in crystals of studied complexes. While dinuclear $\mathbf{3} \cdot \mathbf{M e C N}$ and polynuclear complex $\mathbf{4}^{\star *}$ achieve intermolecular bonding through coordination of amino group to the sixth coordination place of $\left\{\mathrm{MoO}_{2}\right\}^{2+}$ core, that same group is responsible for supramolecular dimerization or polymerization in mononuclear complexes (Figures 1, S2, S5). In all cases, hydrogen bonding propagates along all three dimensions, utilizing all available hydrogen bond donors and acceptors, and forming a sturdy metallosupramolecular network.

\subsection{Catalytic study}

Cyclooctene and oct-1-ene were tested as substrates while $\mathrm{H}_{2} \mathrm{O}_{2}$, TBHP in water, and TBHP in decane were used as oxidizing agents. No other organic solvent was added to the reaction mixtures, thus being more in agreement with green chemistry policies. All complexes prepared under mild conditions were used as an epoxidation catalyst and results were summarized in Tables 1 and 2.

\subsubsection{Cyclooctene epoxidation}

Based on the previous investigations and the collected results, the system with aqueous TBHP was taken as the reference one. In reactions with aqueous TBHP, dinuclear complexes 1, 2.MeCN, 3.MeCN and mononuclear complexes 1a - 3a showed high conversions, $83-94 \%$, with selectivity ranging $83-96 \%$. Complexes 4 and 4 a showed lower activity, with conversion values $50-58 \%$. Complex $3^{*} \cdot \mathbf{M e C N}$ showed similar activity as $3 \cdot \mathbf{M e C N}$ and proved to be very selective towards epoxide (Fig. 2). Water from aqueous TBHP does not act as a solvent since, at $80{ }^{\circ} \mathrm{C}$, the $\mathrm{Mo}(\mathrm{VI})$ complexes are soluble in the substrate and not in water. TOF values after $20 \mathrm{~min}$ of the reaction differed from 180 to $406 \mathrm{~h}^{-1}$, while TON after $5 \mathrm{~h}$ of the reaction was between 358 and 365, except for catalyst obtained from $\mathrm{H}_{2} \mathrm{~L}^{4}$ ligand (TOF $20 \mathrm{~min} 36 \mathrm{~h}^{-1}$ for 4 and $42 \mathrm{~h}^{-1}$ for $\mathbf{4 a}$, while TON was 234 for 4 and 270 for $\mathbf{4 a}$ ). Water seems to inhibit partially the catalyst's reactivity or does not allow the reactants to be efficiently close (several H-bonds can occur with water and not with decane). As expected, with TBHP in decane, studied catalytic 
parameters showed higher, even exceptional values (again with the reverse behaviour for $\mathbf{4}$ and 4a). Since the epoxidation reaction was finished within $30 \mathrm{~min}$, samples were taken at a shorter time interval than for the reactions with $\mathrm{H}_{2} \mathrm{O}_{2}$ and aqueous TBHP. We draw attention to extraordinary $\mathrm{TOF}_{2.5}$ min values for dinuclear complex 1a, 2a, and 3.MeCN, reaching 8119 $9556 \mathrm{~h}^{-1}$ value with $0.25 \mathrm{~mol} \%$ [Mo] loading. On contrary to the procedure with TBHP in decane, $\mathrm{H}_{2} \mathrm{O}_{2}$ was not an efficient oxidant with the studied catalysts, as seen from Table 1. However, the results with $\mathrm{H}_{2} \mathrm{O}_{2}$ are of great importance since the research within very similar complexes, respecting the green chemistry principles, has not provided any positive results so far.

It can be concluded, that more soluble complexes, have higher activity. Dinuclear complexes 1 and 2-MeCN showed higher cis-cyclooctene conversion, but the mononuclear complexes 1a and 2a had higher selectivity towards cyclooctene oxide (Figures S6 and S7). This suggests that a faster formation of the catalytically active pentacoordinate $\left[\mathrm{MoO}_{2} \mathrm{~L}\right]$ species is achieved when the (pre)catalysts were more soluble and when the reaction media did not compete with the reactants for the sixth coordination place.

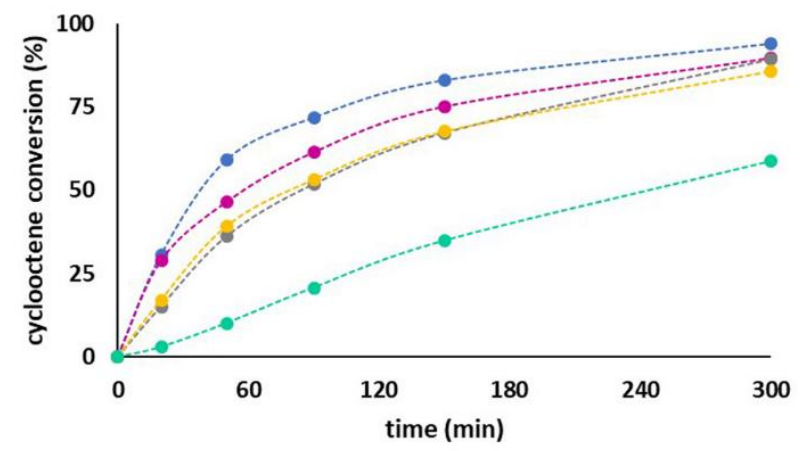

Fig. 2. Converted cyclooctene vs. time with molybdenum(VI) catalysts 1-4 and aqueous TBHP. Conditions: $\mathrm{Mo} /$ cyclohexene/TBHP $=0.25 / 100 / 200, \mathrm{~T}=80^{\circ} \mathrm{C}$. Complex 1 - blue, complex 2 - magenta, complex $\mathbf{3}-$ grey, complex $\mathbf{3}^{\star}$ yellow, complex 4 - green. 
Table 1. Results of the cyclooctene epoxidation catalysed with $\mathrm{Mo}(\mathrm{VI})$ complexes in the presence of three different oxidants.

\begin{tabular}{|c|c|c|c|c|c|}
\hline $\begin{array}{l}\text { Mo } \\
\text { catalyst }\end{array}$ & oxidant & $\begin{array}{l}\text { cyclooctene } \\
\text { conversion } \\
/ \%{ }^{c}\end{array}$ & $\begin{array}{l}\text { epoxide } \\
\text { selectivity } \\
/ \% d\end{array}$ & $\begin{array}{l}\text { TOF }_{20 \min }{ }^{\mathrm{e}} \\
\text { or } \\
\text { TOF }_{2.5 \min }{ }^{\mathrm{f}} \\
/ \mathrm{h}^{-1}\end{array}$ & TON $^{g}$ \\
\hline $1^{a}$ & \multirow{9}{*}{ 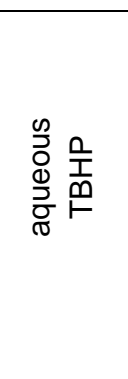 } & 94 & 83 & $370^{e}$ & 378 \\
\hline $1 a^{a}$ & & 93 & 90 & $406^{e}$ & 365 \\
\hline $2 \cdot \mathrm{MeCN}^{\mathrm{a}}$ & & 90 & 82 & $346^{e}$ & 357 \\
\hline $2 a^{a}$ & & 91 & 87 & $332^{e}$ & 362 \\
\hline $3 \cdot \mathrm{MeCN}^{\mathrm{a}}$ & & 89 & 89 & $183^{e}$ & 358 \\
\hline $3^{*} \cdot \mathrm{MeCN}^{\mathrm{a}}$ & & 86 & 96 & $204^{e}$ & 339 \\
\hline $3 \mathbf{a}^{\mathrm{a}}$ & & 83 & 94 & $179 e$ & 360 \\
\hline $4^{a}$ & & 58 & 92 & $36^{e}$ & 234 \\
\hline $4 a^{a}$ & & 50 & 85 & $42^{e}$ & 270 \\
\hline $1^{b}$ & \multirow{7}{*}{ 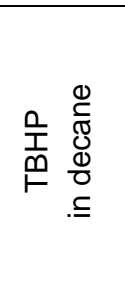 } & \multirow{6}{*}{$<99$} & 91 & $1005^{f}$ & \\
\hline $1 a^{b}$ & & & 92 & $9415^{f}$ & 400 \\
\hline $2 \cdot \mathrm{MeCN}^{\mathrm{b}}$ & & & 93 & $1197^{f}$ & \\
\hline $2 a^{b}$ & & & 89 & $9556^{f}$ & \\
\hline $3 \cdot \mathrm{MeCN}^{\mathrm{b}}$ & & & 90 & $8119^{f}$ & 367 \\
\hline $3^{*} \cdot \mathrm{MeCN}^{\mathrm{b}}$ & & & 95 & $2445^{\mathrm{e}}$ & 354 \\
\hline $4^{b}$ & & 13 & 57 & $106^{f}$ & 50 \\
\hline $1^{a}$ & \multirow{7}{*}{$\begin{array}{l}\text { ON } \\
\text { I }\end{array}$} & 12 & 20 & $13^{e}$ & 49 \\
\hline $1 a^{a}$ & & 5 & 52 & $22^{e}$ & 20 \\
\hline $2 \cdot \mathrm{MeCN}^{\mathrm{a}}$ & & 10 & 26 & $7^{e}$ & 41 \\
\hline $2 a^{a}$ & & 7 & 49 & $16^{e}$ & 27 \\
\hline $3 \cdot \mathrm{MeCN}^{\mathrm{a}}$ & & 16 & 23 & $9^{e}$ & 62 \\
\hline $3^{*} \cdot \mathrm{MeCN}^{\mathrm{a}}$ & & 15 & 16 & $49^{e}$ & 61 \\
\hline $4^{a}$ & & 16 & 14 & $96^{\mathrm{e}}$ & 63 \\
\hline
\end{tabular}

[a] Reaction conditions: time, $5 \mathrm{~h}$; temperature, $80{ }^{\circ} \mathrm{C}$, [Mo]/cyclooctene/oxidant molar ratio: 0.25/100/200. [b] Reaction conditions: time, $20 \mathrm{~min}$; temperature, $80^{\circ} \mathrm{C}$, [Mo]/cyclooctene/oxidant molar ratio: 0.25/100/200. [c] cyclooctene consumed at the end of reaction. [d] Formed epoxide per converted olefin at the end of reaction. [e] $n(c y c l o o c t e n e)$ transformed/ $n$ (catalyst)/time(h) calculated at 20 minutes. [f] $n$ (cyclooctene) transformed/ $n$ (catalyst)/time(h) calculated at 2.5 minutes. $[\mathrm{g}] n$ (cyclooctene) transformed/ $n$ (catalyst) at the end of reaction.

For the comparison, reported catalytic studies of Mo dinuclear and mononuclear complexes with similar ligands obtained from 2-amino-[8] and 4-aminobenzhydrazides ${ }^{[9]}$ provided not so good results in terms of all catalytic parameters. It should be pointed out that from all investigated complexes, the dinuclear Mo compounds presented herein achieved the best TOF 20 min values. Furthermore, complexes obtained from 2-aminobenzhydrazides are in general more active and selective towards epoxide. 


\subsubsection{Oct-1-ene epoxidation}

The second substrate tested under the same conditions was oct-1-ene. Dinuclear compounds were chosen as catalysts. The obtained catalytic parameters presented in Table 2 were not as great as with cyclooctene. With the assistance of TBHP in decane, the main products of catalysed oxidation detected in the organic phase are 1,2-epoxyoctane (a major one) and, in small but relevant quantity, heptan-1-al (due to oxidative $\mathrm{C}=\mathrm{C}$ cleavage), Table S8. Furthermore, Fig. 3 confirms the reaction mechanism and epoxide ring-opening during the time. In the catalytic procedure with catalyst $\mathbf{1}$, after $90 \mathrm{~min}$ of the reaction, epoxide quantity decreased while aldehyde quantity increased. After $6 \mathrm{~h}$ of the reaction, heptan-1-al quantity reached its maxima with a $50 \%$ selectivity towards heptan-1-al. Reaction prolongation to $24 \mathrm{~h}$ favours the formation of by-products that could not be detected with GC (assumed from the mass balance decrease). When comparing oxidants, the same trend between tested parameters can be noticed as in the case of cyclooctene epoxidation: TBHP in decane provides the best results in terms of conversion and selectivity towards epoxide, followed by the use of TBHP in water (Fig. 4). Neither in the case of TBHP in water, nor $\mathrm{H}_{2} \mathrm{O}_{2}$, clear formation of heptan-1-al could be noticed (Figures S8, S9). We can postulate that water and oxidant provoke the further oxidation of the aldehyde and formation of the corresponding carboxylic acid, present in the water phase, but not quantified.

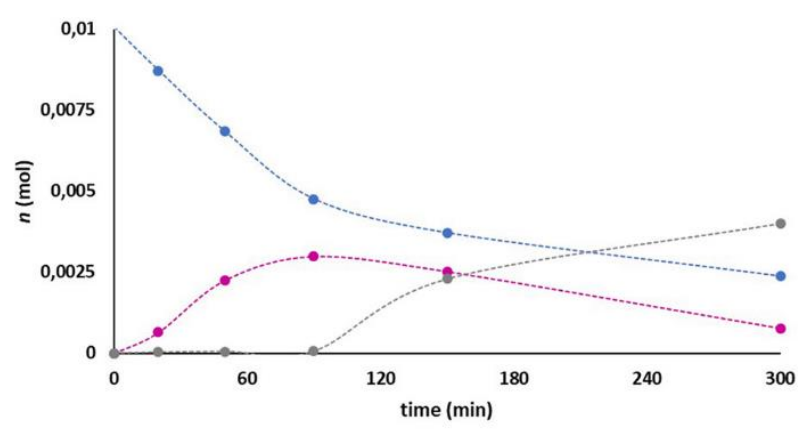

Fig. 3. Converted oct-1-ene (blue curve), formed 1,2-epoxyoctane (magenta curve) and heptan-1-al (grey curve) vs. time with molybdenum(VI) catalysts 1 and TBHP in decane. Conditions: Mo/cyclohexene/TBHP $=0.25 / 100 / 200, T=80{ }^{\circ} \mathrm{C}$. 
Table 2. Results of the oct-1-ene epoxidation catalysed with $\mathrm{Mo}(\mathrm{VI})$ complexes in the presence of three different oxidants.

\begin{tabular}{|c|c|c|c|c|c|}
\hline & & & & & \\
\hline Mo catalyst & oxidant & $\begin{array}{l}\text { oct-1-ene } \\
\text { conversion / } \\
\% c\end{array}$ & $\begin{array}{l}\text { epoxide } \\
\text { selectivity / } \\
\%^{d}\end{array}$ & $\begin{array}{l}\operatorname{TOF}_{20 \min ^{\mathrm{e}}}{ }^{\mathrm{T}} / \\
\mathrm{h}^{-1}\end{array}$ & TON $^{f}$ \\
\hline $1^{a}$ & \multirow{5}{*}{ 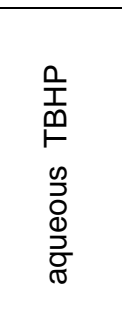 } & 41 & 12 & 51 & 49 \\
\hline $2 \cdot \mathrm{MeCN}^{\mathrm{a}}$ & & 6 & 20 & 30 & 24 \\
\hline $3 \cdot \mathrm{MeCN}^{\mathrm{a}}$ & & 34 & 29 & 36 & 142 \\
\hline $3^{\star} \cdot \mathrm{MeCN}^{\mathrm{a}}$ & & 9 & 84 & 34 & 34 \\
\hline $4^{a}$ & & 10 & 13 & 49 & 16 \\
\hline $1^{b}$ & \multirow{5}{*}{ 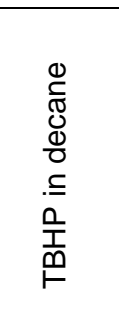 } & 32 & 70 & 146 & 117 \\
\hline $2 \cdot \mathrm{MeCN}^{\mathrm{b}}$ & & 80 & 53 & 889 & 335 \\
\hline $3 \cdot \mathrm{MeCN}^{\mathrm{b}}$ & & 71 & 64 & 297 & 286 \\
\hline $3^{*} \cdot \mathrm{MeCN}^{b}$ & & 82 & 51 & 820 & 317 \\
\hline $4^{b}$ & & 31 & 11 & 44 & 119 \\
\hline $1^{c}$ & \multirow{5}{*}{$\begin{array}{l}\text { OÑ } \\
\text { I }\end{array}$} & 11 & 1 & 48 & 44 \\
\hline $2 \cdot \mathrm{MeCN}^{\mathrm{c}}$ & & 10 & 1 & 40 & 41 \\
\hline $3 \cdot \mathrm{MeCN}^{\mathrm{c}}$ & & 9 & - & 35 & 38 \\
\hline $3^{*} \cdot \mathrm{MeCN}^{\mathrm{c}}$ & & 11 & - & 8 & 42 \\
\hline $4^{c}$ & & 5 & 2 & 23 & 19 \\
\hline
\end{tabular}

[a] Reaction conditions: time, $5 \mathrm{~h}$; temperature, $80{ }^{\circ} \mathrm{C}$, [Mo]/cyclooctene/oxidant molar ratio: 0.25/100/200. [b] Reaction conditions: time, $50 \mathrm{~min}$; temperature, $80^{\circ} \mathrm{C}$, [Mo]/cyclooctene/oxidant molar ratio: 0.25/100/200. [c] oct-1-ene consumed at the end of reaction. [d] Formed epoxide per converted olefin at the end of reaction. [e] $n$ (oct-1-ene) transformed $/ n$ (catalyst)/time(h) at 20 minutes. [f] $n$ (oct-1-ene) transformed $/ n$ (catalyst) at the end of reaction.

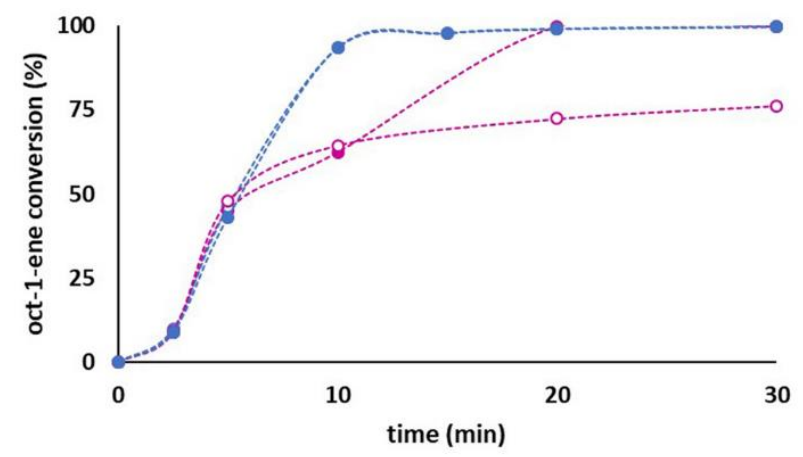

Fig. 4. Converted cyclooctene and oct-1-ene vs. time with molybdenum(VI) catalysts 1 and 2 and TBHP in decane. Conditions: $\mathrm{Mo} /$ cyclohexene/TBHP $=0.25 / 100 / 200, \mathrm{~T}=80^{\circ} \mathrm{C}$. Complex $1-$ blue curve, complex $2-$ magenta curve. The coloured dot presents the reaction with cyclooctene, white circle presents the reaction with oct-1-ene as a substrate. 


\subsection{Mechanistic study}

\subsubsection{TBHP as an oxidant}

The collected experimental data pointed out better activity with cyclooctene and TBHP (in water or decane) for complexes 1-3 than for 4. In the case of oct-1-ene, the results seem to be strongly correlated to the nature of the TBHP carrier (water or decane). Reactivities are strongly solubility-dependent, but activity towards an olefin with TBHP (in decane or water) depends also on the nature of the ligand. A mechanism of the TBHP approach to a similar Mo complex had been previously proposed considering TBHP stabilisation of Mo atom through $\mathrm{O}_{\beta}$ (close to $t \mathrm{Bu}$ ), before $\mathrm{O}_{\alpha}$ (close to $\mathrm{H}$ ) transfers from peroxide to olefin (Scheme S3). ${ }^{[7]}$ Published calculations (in gas phase) with several types of complexes assessed trends according to experiments and ligand substitution. The $\mathrm{OH}^{[23]}$ or $\mathrm{OMe}^{[24,25]}$ present on the aldehyde part helped the reaction to be faster while $\mathrm{NEt}_{2}$ had a reverse effect. ${ }^{[26]}$ The presence of $\mathrm{NO}_{2}$ groups on aminophenol ligand part showed higher activities. ${ }^{[25]}$ Based on the starting reagents, two parts of the studied tridentate ligands, aldehyde (ald) and hydrazide (hyd) can be defined (Scheme 3). DFT calculations with TBHP as oxidant were performed under three specific conditions. Calculation $G$ was done in the gas phase, considering that present water does not interfere with the process and does not act as a solvent. Two other polarizable continuum model $(\mathrm{pcm})$ corrections were added to model solvation effects, one in decane medium, $\mathbf{D}$, to mimic the reactivity with TBHP in decane and one in a water medium, $\mathbf{W}$, to see if water influences the process (through dielectric constant). Calculations revisited the previously postulated pathways. The recalculated geometries have been indicated in Table S19-S13. For Mo-containing species, it was possible to calculate the geometries of $\left[\mathrm{MoO}_{2} \mathrm{~L}\right]([\mathrm{Mo}]),\left[\mathrm{MoO}_{2} \mathrm{~L}(\mathrm{TBHP})\right]\left(\mathrm{I}_{\mathbf{A}}\right)$, and the transition states (TS) under $\mathbf{G} / \mathbf{D} / \mathbf{W}$ conditions. The $[\mathrm{MoOL}(\mathrm{OH})(\mathrm{OtBu})](\mathbf{I T})$ intermediates could be calculated under $\mathbf{G} / \mathbf{D}$ conditions only. Thus, two mechanisms are summarized in Scheme S3, one with the It intermediate (for $\mathbf{G}$ and $\mathbf{D}$ ) and one without (for $\mathbf{W}$ ) with a direct release of $t \mathrm{BuOH}$ within the process.
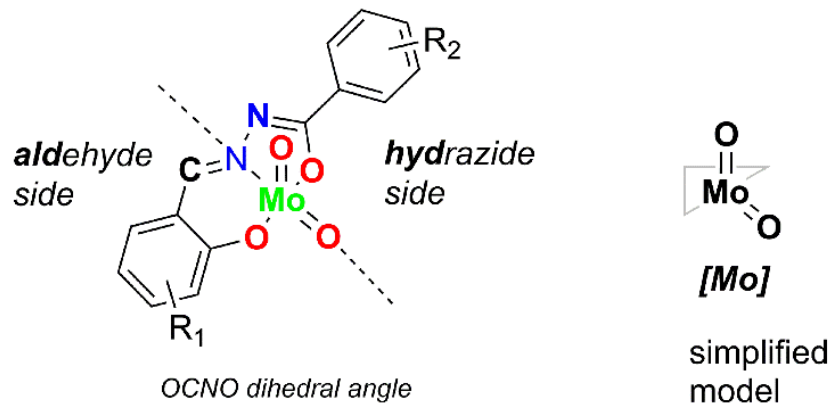

Scheme 3. $\left[\mathrm{MoO}_{2} \mathrm{~L}\right]$ pentacoordinated species with the distinction of the aldehyde (ald) and hydrazide (hyd) side as well as the four atoms considered for the dihedral angles in bold on the ligand (left). The triangle around Mo (right) defines the ONO coordination of the ligand around the metal. 
Relevant enthalpy changes $(\Delta H)$ have been presented in Table 3 , while enthalpies $(\Delta H)$ energies $(\Delta E)$ and free energies values $(\Delta G)$ of the complete process have been listed in Table S8. To be consistent with our previous works the discussion will consider enthalpies, while the conclusions with free energies are identical. ${ }^{[7]}$ The $\Delta H$ values of each process under $\mathbf{G} / \mathbf{D} / \mathbf{W}$ conditions, and especially TS in the case of the reaction issued from $\left[\mathrm{MoO}_{2} \mathrm{~L}^{1}\right]$ pentacoordinate species, were the lowest (the most favourable path), while the highest values (less favourable path) were found for complexes prepared from $\left[\mathrm{MoO}_{2} \mathrm{~L}^{4}\right](\mathbf{G} / \mathbf{D})$ and $\left[\mathrm{MoO}_{2} \mathrm{~L}^{3}\right](\mathbf{W})$ species, which agrees with the experimental data. The observed behaviour can be linked to the nature of the substitution on the ligand and/or to the geometry around Mo. The presence of $\mathrm{OH}$ on the $3 \mathrm{C}$ atom seems to be favourable under $\mathbf{D} / \mathbf{W}$ conditions. Although the enthalpy difference between processes using $\left[\mathrm{MoO}_{2} \mathrm{~L}^{2}\right]$ and $\left[\mathrm{MoO}_{2} \mathrm{~L}^{3}\right]$ species (G conditions) is not so high, the comparison can be done between the processes implying $\left[\mathrm{MoO}_{2} \mathrm{~L}^{1}\right]$ and $\left[\mathrm{MoO}_{2} \mathrm{~L}^{4}\right]$ species. The position of the pending $\mathrm{NH}_{2}$ seems to have strong importance due to the hydrogen bond between the hydrazone and $\mathrm{NH}_{2}$ linked to $10 \mathrm{C}$, stabilizing the complex and consequently providing better catalytic activity.

Table 3. Relevant results of the enthalpy values $\Delta H(\mathrm{kcal} / \mathrm{mol})$ of different steps obtained through DFT calculations for ethylene epoxidation using TBHP as oxidant and catalysed with $\mathrm{Mo}(\mathrm{VI})$ complexes under the different conditions $(\mathbf{G} / \mathbf{D} / \mathbf{W})$.

\begin{tabular}{|c|c|c|c|c|c|}
\hline \multirow[b]{3}{*}{ G } & & \multicolumn{4}{|c|}{ according to $\left[\mathrm{MoO}_{2} \mathrm{~L}\right]^{\mathrm{n}}$} \\
\hline & Reaction Steps & $\mathrm{L}^{1}$ & $\mathrm{~L}^{2}$ & $\mathrm{~L}^{3}$ & $\overline{\mathrm{L}^{4}}$ \\
\hline & $\begin{array}{l}{[\mathrm{Mo}]+T B H P=I_{A}} \\
I_{A}+\mathrm{C}_{2} \mathrm{H}_{4}=T S\end{array}$ & $\begin{array}{l}-8.5 \\
+23.5\end{array}$ & $\begin{array}{l}-8.5 \\
+24.2\end{array}$ & $\begin{array}{l}-8.4 \\
+23.9\end{array}$ & $\begin{array}{l}-8.4 \\
+24.6\end{array}$ \\
\hline D & $\begin{array}{l}{[\mathrm{Mo}]+T B H P=I_{A}} \\
I_{A}+C_{2} H_{4}=T S\end{array}$ & $\begin{array}{l}-6.5 \\
+23.1\end{array}$ & $\begin{array}{l}-6.6 \\
+23.9\end{array}$ & $\begin{array}{l}-6.3 \\
+23.9\end{array}$ & $\begin{array}{l}-6.4 \\
+24.6\end{array}$ \\
\hline W & $\begin{array}{l}{[\mathrm{Mo}]+T B H P=I_{A}} \\
I_{A}+C_{2} H_{4}=T S\end{array}$ & $\begin{array}{l}-5.5 \\
+27.9\end{array}$ & $\begin{array}{l}-5.4 \\
+28.1\end{array}$ & $\begin{array}{l}-4.9 \\
+28.4\end{array}$ & $\begin{array}{l}-5.2 \\
+28.3\end{array}$ \\
\hline
\end{tabular}

A geometrical discussion has been added before Table S14. It can be concluded that the trend under the three experimental conditions is the same among $\mathrm{MoO}_{2} \mathrm{~L}$ species. The $\mathbf{G}$ and $\mathbf{D}$ calculations seem to express qualitative results following the nature of the ligand and fitting with experimental data. The $\mathbf{W}$ conditions increase the $\mathbf{T S}$ values for all ligands. Since the calculation under $\mathbf{G}$ condition seems to be good enough to compare activity among ligands, all calculations with $\mathrm{H}_{2} \mathrm{O}_{2}$ as oxidant have been performed under $\mathbf{G}$ conditions.

\subsection{2. $\mathrm{H}_{2} \mathrm{O}_{2}$ as an oxidant}

The mechanism with $\mathrm{H}_{2} \mathrm{O}_{2}$ as an oxidant was not as trivial. The nature of $\mathrm{H}_{2} \mathrm{O}_{2}$ brings several possibilities inherent to two labile hydrogens, acting as a potential proton transfer shuttle, a phenomenon not seen in the case of TBHP. The presence of the peroxo complex $\left(\eta^{2}-\mathrm{O}\right)$, described by several groups as a very active (pre)catalyst able to transfer the oxygen atom to form the epoxide, had to be considered. ${ }^{[27-33]}$ In this investigation, the starting compound is not a peroxo species, but a peroxo compound might be formed in situ. For that, different scenarios of active intermediates and their approach to the olefin are proposed starting from [ $\left.\mathrm{MoO}_{2} \mathrm{~L}\right]$ [Mo] species to the final oxo-peroxo one $\left[\mathrm{MoO}\left(\mathrm{O}_{2}\right) \mathrm{L}\right] \mathbf{l} \mathbf{l c}$. The monoperoxo intermediate $\mathbf{I c}$ was chosen since it is supposed to be more active than the bis(peroxo) compound. ${ }^{[34]}$ Besides, the bis- 
peroxo would need more steps and pathways. All calculations were done under $\mathbf{G}$ conditions only since the aim was a comparison between ligands and not precise numerical data.

Intermediates. We considered previously DFT-studied mechanisms for the intermediates. Calculation assumptions started from the interaction of $\mathrm{H}_{2} \mathrm{O}_{2}$ with $\mathrm{MoO}_{2} \mathrm{~L}$ [Mo], as proposed with TBHP, forming the $\left[\mathrm{MoO}_{2} \mathrm{~L}\left(\mathrm{H}_{2} \mathrm{O}_{2}\right)\right]$ adduct $\mathrm{I}_{\mathrm{A}} \cdot{ }^{[7]}$ From this adduct, there is the possibility of the formation of a hydroperoxo-hydroxo-oxo molybdenum complex $[\mathrm{MoO}(\mathrm{OH})(\mathrm{OOH}) \mathrm{L}] \mathrm{IB}_{\mathbf{B}}{ }^{[27]}$ The intermediate lB can lead to the oxo-peroxo $\left[\mathrm{MoO}\left(\mathrm{O}_{2}\right) \mathrm{L}\right] \mathrm{Ic}$ species through the release of one water molecule. ${ }^{[27-33]}$ The intermediates $I_{A}$, $I_{B}$ and $I_{C}$ have been calculated in the gas phase (Scheme 4).

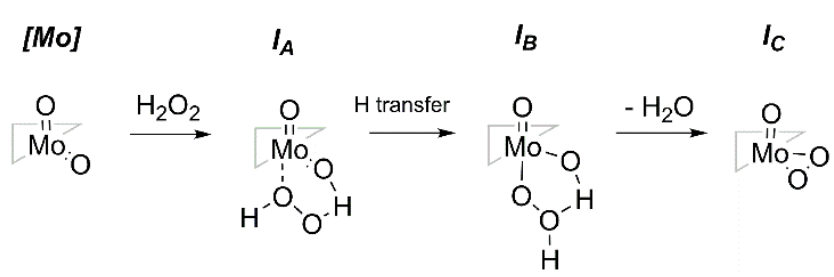

Scheme 4. Scheme presenting the different intermediates.

An additional feature has been added herein, starting from a phenomenon due to the addition of $\mathrm{H}_{2} \mathrm{O}_{2}$. The $(\mathrm{Mo}=\mathrm{O} \cdots \mathrm{H}-\mathrm{O}-\mathrm{O}) \cdot 5$-membered ring formed could be schemed as a pseudo plane almost perpendicular to the ligand, with the hydrazide part on one side of the pseudo plan and the aldehyde moiety on the other side. Thus, the pending $\mathrm{H}$ (from hydrogen peroxide) not involved in coordination can be situated on the side of hydrazide or the side of the aldehyde part, Scheme 3.

Thus, the $\mathrm{H}$ position will be distinguished for $\mathbf{I}_{\mathbf{A}}$ and $\mathbf{I}_{\mathbf{B}}$, doubling the number of intermediates with $I_{\mathbf{A}(\text { hyd) }}$ and $I_{\mathbf{A}(\text { ald), }} I_{\mathbf{B}(\text { hyd) }}$ and $I_{B(\text { (ad) }}$.

The approach of $\mathrm{C}_{2} \mathrm{H}_{4}$ has been examined and three paths ( $\mathrm{A}, \mathrm{B}$ and $\left.\mathrm{C}\right)$ have been calculated, respectively named from their corresponding intermediates, $I_{A}$, IB and Ic. As for TBHP, relevant calculated enthalpies $(\Delta H)$ were compiled in Table 5 , (with all other data $\Delta E, \Delta H$ and $\Delta G$ collected in Table S11). An energetic profile was indicated Scheme 5.

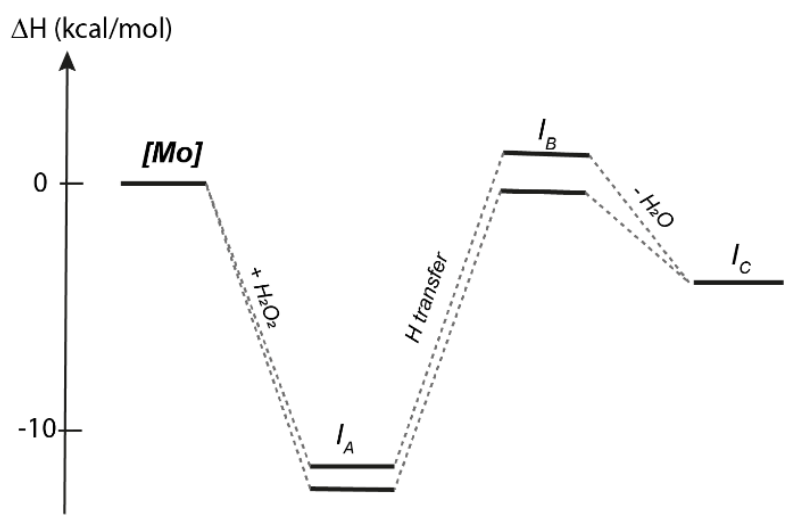

Scheme 5. Relative enthalpies considering the three intermediates in the case of $\left[\mathrm{MoO}_{2} \mathrm{~L}^{1}\right]$. 
The approach of $\mathrm{H}_{2} \mathrm{O}_{2}$ to [Mo] forms $\mathrm{I}_{A}$ and stabilized the system with ca. $12.2 \mathrm{kcal} / \mathrm{mol}(-11.9$ to $-12.4 \mathrm{kcal} / \mathrm{mol}$ range), the most stable ones being with the pending $\mathrm{H}$ (linked to $\mathrm{O}_{\beta}$ ) on ald side. The transformation of $I_{A}$ to $I_{B}$ costs between 12.2 and $13.3 \mathrm{kcal} / \mathrm{mol}$. Since water molecules present in the reaction mixture could act as a shuttle, determination of a transition step with one water molecule would give overestimated TS values and were thus not calculated. However, $\mathbf{I}_{\mathbf{B}}$ is higher in energy compared to $I_{A}$. In the case of the $I_{\mathbf{C}}$ formation, the formal dehydration of $\mathbf{I}_{\mathbf{B}}$ stabilizes Ic (compared to lB) from 2.7 to $5.1 \mathrm{kcal} / \mathrm{mol}$.

From the three intermediates, three different paths of the approach of $\mathrm{C}_{2} \mathrm{H}_{4}$ were described (Scheme 6-8).

Path A (Scheme 6), from $I_{A}$ intermediate, is very close to the approach with TBHP presented above (Scheme S3). Thus, $\mathbf{T S}_{\mathbf{A}}$ corresponds to a 5-membered ring intermediate with an $\mathrm{H}$ transfer of the $\mathrm{H}$-bonded hydrogen interacting with the oxo atom present in the plane of the ligand (formation of hydroxo group) while the dative bond between $\mathrm{O}_{\beta}$ and Mo becomes covalent with the formation of second hydroxo group on Mo. The species obtained after the TS corresponds to $\left[\mathrm{MoO}(\mathrm{OH})_{2} \mathrm{~L}(\mathrm{epo})\right]$. The regeneration of $[\mathrm{Mo}]$ is obtained in a 2-steps process releasing first the epoxide.

Table 5. Results of relevant DFT calculated enthalpies $\Delta \mathrm{H}$ (in $\mathrm{kcal} / \mathrm{mol}$ ) for ethylene epoxidation catalysed with $\mathrm{MoO}_{2} \mathrm{~L}$ complexes [Mo] (with $\mathrm{H}_{2} \mathrm{O}_{2}$ as an oxidant)

\begin{tabular}{|c|c|c|c|c|c|}
\hline & & \multicolumn{4}{|c|}{ according to $\left[\mathrm{MoO}_{2} \mathrm{~L}\right] \mathrm{n}$} \\
\hline & Reaction & $\mathrm{L}^{1}$ & $\mathrm{~L}^{2}$ & $\mathrm{~L}^{3}$ & $\mathrm{~L}^{4}$ \\
\hline \multirow{6}{*}{ 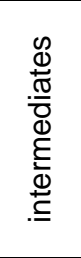 } & {$[\mathrm{Mo}]+\mathrm{H}_{2} \mathrm{O}_{2}=I_{A(h y d)}$} & -12.1 & $-11,9$ & $-12,2$ & $-12,0$ \\
\hline & {$[\mathrm{Mo}]+\mathrm{H}_{2} \mathrm{O}_{2}=I_{A(a l d)}$} & -12.2 & $-12,2$ & $-12,4$ & $-12,3$ \\
\hline & $I_{A(h y d)}=I_{B(h y d)}$ & $+13,0$ & $+13,0$ & $+12,6$ & $+13,3$ \\
\hline & $I_{A(a l d)}=I_{B(a l d)}$ & $+12,1$ & $+12,3$ & $+12,1$ & $+12,2$ \\
\hline & $I_{B(\text { hyd })}=I_{C}+\mathrm{H}_{2} \mathrm{O}$ & $-4,6$ & $-5,1$ & $-3,4$ & $-4,5$ \\
\hline & $I_{B(a l d)}=I_{C}+H_{2} \mathrm{O}$ & $-3,7$ & $-4,1$ & $-2,7$ & $-3,1$ \\
\hline \multirow{2}{*}{$\stackrel{F}{\stackrel{D}{\sigma}}<$} & $I_{A(h y d)}+C_{2} H_{4}=T S_{A(h y d)}$ & $+17,3$ & $+17,9$ & $+17,9$ & $+18,4$ \\
\hline & $I_{A(\text { ald })}+C_{2} H_{4}=T S_{A(a l d)}$ & $+17,3$ & $+17,9$ & $+17,9$ & $+18,5$ \\
\hline \multirow{2}{*}{ 禁 } & $I_{B(h y d)}+C_{2} H_{4}=T S_{B(h y d)}$ & $+20,1$ & $+20,2$ & $+20,7$ & $+20,2$ \\
\hline & $I_{B(\text { ald })}+C_{2} H_{4}=T S_{B(\text { ald })}$ & $+23,6$ & $+23,7$ & $+24,3$ & $+24,4$ \\
\hline \multirow{2}{*}{ 养 } & $I_{C}+C_{2} H_{4}=T S_{C(h y d)}$ & $+24,6$ & $+24,9$ & $+25,3$ & $+25,6$ \\
\hline & $I_{C}+\mathrm{C}_{2} \mathrm{H}_{4}=T S_{C(\text { ald })}$ & $+23,4$ & $+24,0$ & $+24,2$ & $+24,7$ \\
\hline
\end{tabular}

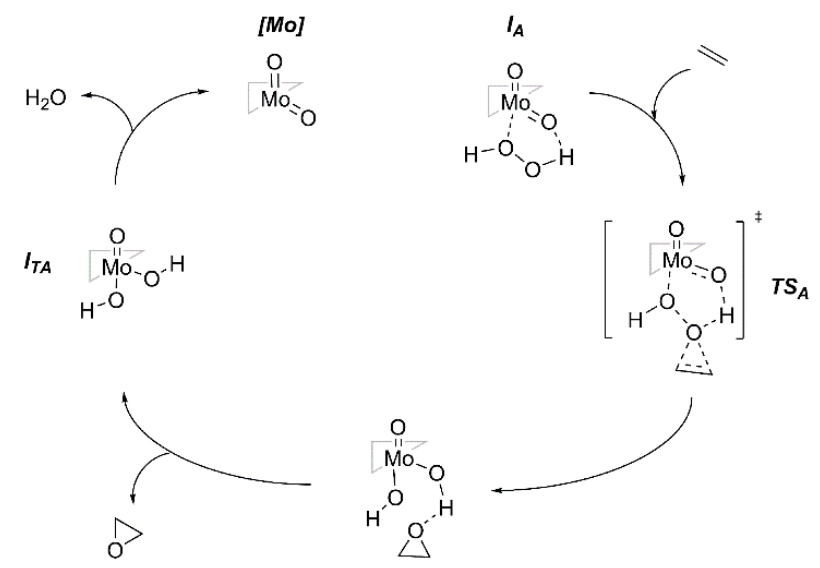

Scheme 6. Summary of the mechanism calculated with all ligands in the case of path A. [Mo], IA, TSA and ITA abbreviations depicted in the schemes are the ones present in all the tables. 
Path $\mathrm{B}$ (Scheme 7) takes the advantage of the $\mathrm{H}$-bond present between the $\mathrm{OH}$ and the $\mathrm{OOH}$ moieties linked to Mo on the $I_{B}$ intermediate. The species formed after the $\mathbf{T S}_{\boldsymbol{B}}$ corresponds to the $[\mathrm{Mo}](\mathrm{epo})\left(\mathrm{H}_{2} \mathrm{O}\right)$ with the water molecule interacting differently if considering hyd or ald side.

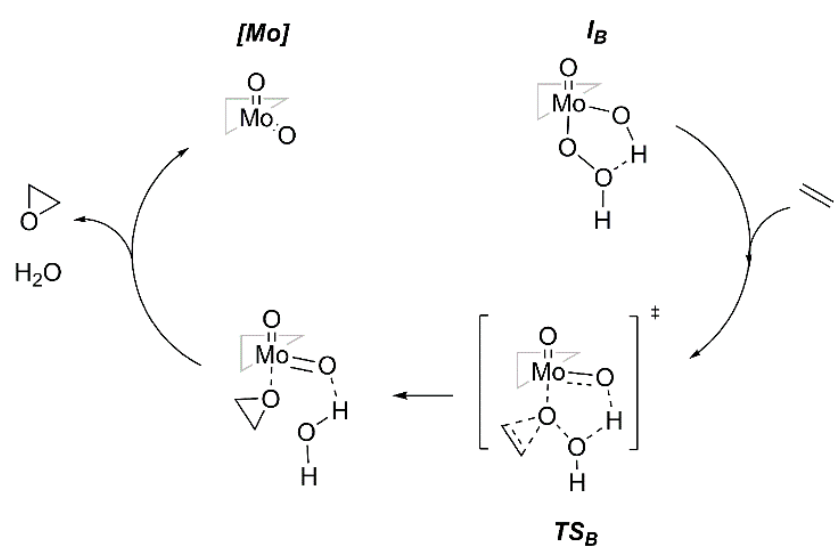

Scheme 7. Summary of the mechanism calculated with all ligands in the case of path $\mathrm{B}$. [Mo], $\mathbf{I}_{\mathrm{B}}, \mathrm{TS}_{\mathrm{B}}$ and $\boldsymbol{I}_{T B}$ abbreviations depicted in the schemes are the ones present in all the tables.

Path C, related to Ic intermediate, leads to two TS depending on approach on hyd side or ald side, ${ }^{[35-44]}$ related to Sharpless process. ${ }^{[16]}$ (Scheme 3 and 8 ) The compound after the TS corresponds to the [Mo] and the epo, with a propension to form hydrogen bond on ald side, because of the proximity of the $\mathrm{OH}$ bond in the case of complexes obtained from ligands $\mathrm{H}_{2} \mathrm{~L}^{1}$ and $\mathrm{H}_{2} \mathrm{~L}^{2}$.

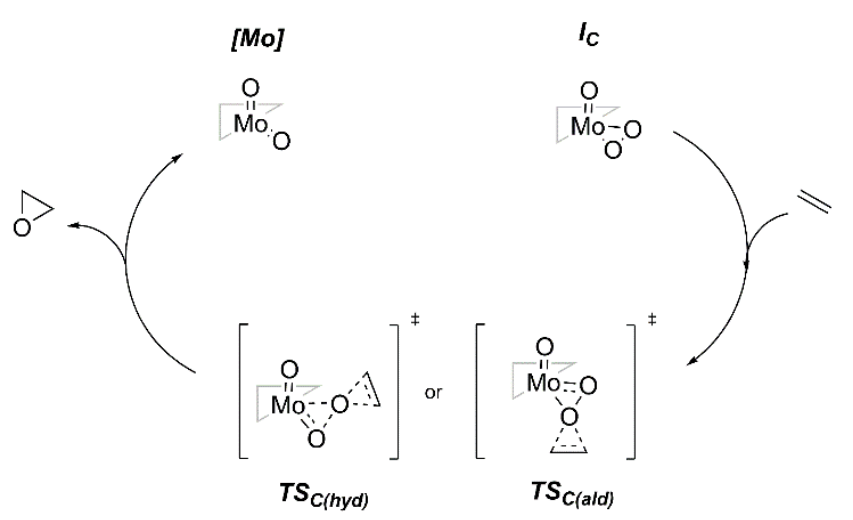

Scheme 8. Summary of the mechanism calculated with all ligands in the case of path $\mathrm{C}$. [Mo], Ic, TSc (hyd and ald) abbreviations depicted in the schemes are the ones present in all the tables.

Enthalpic considerations about the three paths can be done using the TS values from Table 5. The corresponding TS in all the cases is strongly in favour of path A, i.e. the simple interaction between $\mathrm{H}_{2} \mathrm{O}_{2}$ and [Mo] with a median $\mathbf{T S}_{\mathbf{A}}$ value of $17.9 \mathrm{kcal} / \mathrm{mol}$ (no difference between hyd and ald approach) vs. $24.8 \mathrm{kcal} / \mathrm{mol}( \pm 1 \mathrm{kcal} / \mathrm{mol}$, more favoured in case of the hyd approach) for the TSc, in relation with path $C$. As information, path $B$ has a $\mathbf{T S}_{\mathbf{B}}$ value situated between paths $A$ and $C$ but with the average value of $22.2 \pm 2.1 \mathrm{kcal} / \mathrm{mol}$, the hyd approach being more favourable. Relatively to [Mo], path $A$ is the most favourable one with a difference of $15 \mathrm{kcal} / \mathrm{mol}$ compared to paths $B$ and $C$. The trend between the ligand, as for THBP as oxidant, seem to be 
in favour with the processes starting from $\left[\mathrm{MoO}_{2} \mathrm{~L}^{1}\right]$ pentacoordinate species and the less favourable being with the $\left[\mathrm{MoO}_{2} L^{4}\right]$ one. The order values for $T S_{A}<T S_{B}$ are quite similar than with those with TBHP calculated previously for $\left[\mathrm{MoO}_{2}(\mathrm{SAP})\right]\left(\mathrm{TS}_{\mathrm{A}}: 22.5 \mathrm{kcal} / \mathrm{mol}, \mathrm{TS}_{B} 27.2\right.$ $\mathrm{kcal} / \mathrm{mol}) .{ }^{[7]}$ In general, all the TSA values calculated with similar $\mathrm{MoO}_{2} \mathrm{~L}$ models and TBHP lie around $23 \mathrm{kcal} / \mathrm{mol}$. [23,24,26] Values are lower with $\mathrm{H}_{2} \mathrm{O}_{2}$, certainly due to steric factors. Geometrical discussion has been added together with Table S15.

\section{Conclusion}

Different type of mononuclear, dinuclear or polynuclear molybdenum( $\mathrm{VI})$ complexes were prepared by the direct reaction of Mo precursor and amino aroylhydrazones under mild reaction conditions. These compounds were tested as catalysts for cyclooctene and oct-1-ene epoxidation with TBHP and $\mathrm{H}_{2} \mathrm{O}_{2}$ as oxidants. The results confirmed that TBHP in decane is the best oxidant, decane used as an oxidant carrier acting as a solvent. The organic solvent-free oxidation with $\mathrm{H}_{2} \mathrm{O}_{2}$ is possible, but much slower than with TBHP, possibly due to solubility issues. The experimental and DFT studies have confirmed the role of the ligand and the importance of the $\mathrm{NH}_{2}$ functionality and position on the ligands, conspicuous when employing TBHP. When using $\mathrm{H}_{2} \mathrm{O}_{2}$ as an oxidant, the pathway with simple $\mathrm{H}_{2} \mathrm{O}_{2}$ coordination seems to be the most favoured one, and not the peroxo pathway. Further work will be oriented towards the design of other Mo active catalysts employing hydrogen peroxide as an oxidant.

\section{Experimental}

\subsection{Materials and methods}

Solvents and starting reagents (Aldrich) were commercially available and used without previous purification. Ligands were prepared following the published protocol. ${ }^{[19]}$ For catalytic reactions, molar concentrations of used oxidants were: aqueous TBHP, 7.76 M; TBHP in decane, 5.5 M, $30 \% \mathrm{H}_{2} \mathrm{O}_{2}$. Infrared spectra were recorded with Perkin-Elmer 502 spectrophotometer in the region of $4000-400 \mathrm{~cm}^{-1}$, using Attenuated Total Reflectance technique (ATR). All data were processed in Omnic and SpectraGryph program. Thermogravimetric analyses were performed on a Mettler-Toledo TGA/SDTA851 thermobalance using aluminium crucibles, in an oxygen atmosphere and temperature range from 25 to $600^{\circ} \mathrm{C}$, with a heating rate of $10^{\circ} \mathrm{C} \mathrm{min}{ }^{-1}$. The powder X-ray diffraction data were collected by the Panalytical $X$ 'Change powder diffractometer in the Brag-Brentano geometry using $\mathrm{Cu}-\mathrm{K} \alpha$ radiation. Patterns were collected in the range of $2 \theta=5-50^{\circ}$ with a step size of $0.03^{\circ}$ and $1.5 \mathrm{~s}$ per step. All data were collected and visualized using X'pert programs suite. Chromatograms were obtained using Agilent $7820 \mathrm{~A}$ chromatograph with FID detector and HP5-MS capillary column $(30 \mathrm{~m} \times 0.32 \mathrm{~mm} \times 0.25 \mu \mathrm{m})$. The GC parameters were quantified with authentic samples of the reactants and products. After the injection of the sample, it is exposed to a temperature of $50{ }^{\circ} \mathrm{C}$ for 5 minutes, after which it is heated to $220^{\circ} \mathrm{C}$ at a rate of $10^{\circ} \mathrm{C} / \mathrm{min}$. Heater: $270{ }^{\circ} \mathrm{C}, \mathrm{H}_{2}$ flow $30 \mathrm{~mL} / \mathrm{min}$, airflow 280 $\mathrm{mL} / \mathrm{min}$. Conversion of olefins and formation of corresponding epoxides were calculated from 
calibration curves relative to acetophenone as an internal standard. For complexes identification, 1D ( $\left.{ }^{1} \mathrm{H},{ }^{13} \mathrm{C}-\mathrm{APTq}\right)$ and $2 \mathrm{D}$ (COSY, HMQC, HMBC) solution NMR spectra were recorded on Bruker Avance III HD $400 \mathrm{MHz} / 54 \mathrm{~mm}$ Ascend spectrometer equipped with a $5 \mathrm{~mm}$ PA BBI 1H/D-BB Z-GRAD probe head. All measurements were performed at $298 \mathrm{~K}$ using standard Bruker pulse programs. dmso-d6 was used as solvent and TMS as an internal standard.

\subsection{Single-crystal $\mathrm{X}$-ray measurements and structure determinations}

High-quality single crystals of complexes $2 \mathrm{a} \cdot \mathrm{MeOH}, 3 \cdot \mathrm{MeCN}, 3 \mathrm{a}$, and $\mathbf{4}^{\star \star}$, were grown from the reaction mixtures, $2 \mathrm{a} \cdot \mathrm{MeOH}, 3 \mathrm{a}$ and $4^{\star *}$ from $\mathrm{MeOH}$, while $3 \cdot \mathrm{MeCN}$ from $\mathrm{MeCN}$. Diffracted intensities were collected on Oxford Diffraction Xcalibur diffractometer using MoKa radiation $(\lambda$ $=0.71073 \AA$ ) using $\omega$-scans. Data were prepared using the CrysAlis Pro program package. ${ }^{[45]}$ A summary of general and crystal data, intensity data collection and final refinement parameters are presented in Table S7. The structures were solved with dual space methods using $S H E L X T{ }^{[46]}$ The refinement procedure by full-matrix least-squares methods based on $F^{2}$ values against all reflections included anisotropic displacement parameters for all non-H atoms. Hydrogen atoms bound to carbon atoms were placed in geometrically idealized positions and refined by the use of the riding model with $U_{\text {iso }}=1.2 U_{\text {eq }}$ of the connected carbon atom or as ideal $\mathrm{CH}_{3}$ groups with $U_{\text {iso }}=1.5 U_{\text {eq. }}$. Hydrogen atoms attached to oxygen atoms $(\mathrm{O} 2, \mathrm{O} 6$ and O7) and nitrogen atoms (N3) were located in the difference Fourier maps at the final stages of the refinement procedure. Their coordinates were refined freely but with restrained $\mathrm{N}-\mathrm{H}$ distances of 0.86(2) $\AA$ and $\mathrm{O}-\mathrm{H}$ distances of $0.82(2) \AA$. All refinements were performed using SHELXL-2013[47] The SHELX programs operated within the Olex2 suite.[48] Geometrical calculations and molecular graphics were done with Mercury. ${ }^{[49]}$

\subsection{Theoretical calculations}

The geometries of all species under investigation were optimized without any symmetry constraint with the Gaussian 09 rev. D01 program suite, ${ }^{[50]}$ with the DFT approach using the B3LYP three-parameter functional|[1-53] in conjunction with the $6-31 \mathrm{G}^{*}$ basis set ${ }^{[54-57]}$ for the light atoms $(\mathrm{O}, \mathrm{N}, \mathrm{C}, \mathrm{H})$ and the CEP-31G set for the Mo atom. ${ }^{[58,59]}$ The geometries of all complexes and intermediates were optimized from starting geometries determined or inspired by X-ray diffraction without any symmetry constraint. All coordinates have been listed in SI (Tables S13). Frequency analysis confirmed that the optimized geometries of all the stable compounds and intermediates were local minima. The transition states were optimized using a preliminary scan of a relevant internal coordinate, followed by full optimization of the TS guided by the knowledge of such coordinates. All optimized geometries were confirmed to be stationary points and local minima (for stable molecules or reaction intermediates) or first-order saddle points (for the TSs) by frequency analyses. For all the TSs, analysis of the imaginary frequency confirmed the expected motion along the reaction coordinate. Those values and the relative schemes have been added Table S11-S14) The calculated frequencies were also used to derive the thermochemical parameters at $298 \mathrm{~K}$ according to the standard approximations (ideal gas, rigid 
rotor and harmonic oscillator). Solvent effects were included using PCM single point calculations on the gas-phase optimized geometries. ${ }^{[60]}$

\subsection{Preparative part}

Dinuclear complexes $\left[\mathrm{MoO}_{2}(\mathrm{~L})\right]_{2}$ General procedure: $0.083 \mathrm{~g}(0.306 \mathrm{mmol})$ of the $\mathrm{H}_{2} \mathrm{~L}^{1-4}$ ligand was dissolved in $50 \mathrm{~mL}$ of acetonitrile and $0.1 \mathrm{~g}(0.307 \mathrm{mmol})$ of $\left[\mathrm{MoO}_{2}(\mathrm{acac})_{2}\right]$ was added. The orange reaction mixture was refluxed for 3 hours. The obtained product was filtered off.

Complex 1, $\left[\mathrm{MoO}_{2}\left(\mathrm{~L}^{1}\right)\right]$ 2. Yellow product. Yield: $0.104 \mathrm{~g}(86.1 \%)$. Mass fraction of elements, $\mathrm{w}$ / \%, calculated (experimental), for $\mathrm{C}_{28} \mathrm{H}_{22} \mathrm{Mo}_{2} \mathrm{~N}_{6} \mathrm{O}_{10}$, are: $\mathrm{C}, 42.33$ (42.13); $\mathrm{H}, 2.79$ (2.58); $\mathrm{N}$, 10.58 (11.02). Selected IR data $\left(\mathrm{cm}^{-1}\right): 3251,3214\left(\mathrm{NH}_{2}\right), 1614(\mathrm{C}=\mathrm{N}$ imine), $1591(\mathrm{C}=\mathrm{C}), 1341$ (C-O), 1263 (C-Ophenolate), 921, $906\left(\mathrm{MoO}_{2}{ }^{2+}\right), 895(\mathrm{Mo}-\mathrm{N})$. TG: calcd. for $\mathrm{MoO}_{3}, 36.24 \%$, found $37.41 \%$.

Complex 2·MeCN, $\left[\mathrm{MoO}_{2}\left(\mathrm{~L}^{2}\right)\right] 2 \cdot \mathrm{MeCN}$, Yellow-orange product. Yield: $0.1064 \mathrm{~g}(87.8 \%)$. Mass fraction of elements, $\mathrm{w} / \%$, calculated (experimental) for $\mathrm{C}_{30} \mathrm{H}_{25} \mathrm{Mo}_{2} \mathrm{~N}_{7} \mathrm{O}_{10}$, are: $\mathrm{C}, 42.33$ (41.89); $\mathrm{H}, 2.79$ (1.84); N, 10.58 (9.85). Selected IR data $\left(\mathrm{cm}^{-1}\right): 3331\left(\mathrm{NH}_{2}\right), 1602$ (C=Nimine), 1568 $(\mathrm{C}=\mathrm{C}), 1326(\mathrm{C}-\mathrm{O}), 1255$ (C-Ophenolate), 919, $910\left(\mathrm{MoO}_{2}{ }^{2+}\right), 879(\mathrm{Mo}-\mathrm{N})$. TG: calcd. for $\mathrm{MoO}_{3}$, $34.47 \%$, found $37.25 \%$, for MeCN calcd. $4.91 \%$, found $4.98 \%$.

Complex 2, $\left[\mathrm{MoO}_{2}\left(\mathrm{~L}^{2}\right)\right]_{2}$. Complex 2 was obtained after the heating of complex $2 \cdot \mathrm{MeCN}$ at $120^{\circ} \mathrm{C}$ for two hours.

Complex 3· $\mathrm{MeCN},\left[\mathrm{MoO}_{2}\left(\mathrm{~L}^{3}\right)\right] 2_{2} \cdot \mathrm{MeCN}$. Dark red product. Yield: 0,494 g (83\%). Mass fraction of elements, w / \%, calculated (experimental) for $\mathrm{C}_{30} \mathrm{H}_{25} \mathrm{Mo}_{2} \mathrm{~N}_{7} \mathrm{O}_{10}$ : $\mathrm{C} 43.13$ (42.18); H 3.02 (2.06); N 11.74 (11.01). Selected IR data $\left(\mathrm{cm}^{-1}\right)$ : 3311, $3196\left(\mathrm{NH}_{2}\right), 1585$ (C=Nimine), 1199 (COphenolate), 922, $890\left(\mathrm{MoO}_{2}{ }^{2+}\right), 949$ (Mo-N). TG: calcd. for $\mathrm{MoO}_{3}, 34.47 \%$, found $36.70 \%$, for MeCN calcd. $4.91 \%$, found $4.35 \%$.

Complex 3, $\left[\mathrm{MoO}_{2}\left(\mathrm{~L}^{3}\right)\right]_{2}$. Complex 3 was obtained after the heating of complex $3 \cdot \mathrm{MeCN}$ at $160^{\circ} \mathrm{C}$ for two hours.

Complex $3^{*} \cdot \mathrm{MeCN},\left[\mathrm{MoO}_{2}\left(\mathrm{~L}^{3}\right)\right] 2^{2} \cdot \mathrm{MeCN}$ obtained from the more concentrated acetonitrile solution, $V(\mathrm{MeCN})=10 \mathrm{~mL}$. Dark orange-brown product. Yield: 0,550 $\mathrm{g}(92 \%)$. Mass fraction of elements, w / \%, calculated (experimental) for $\mathrm{C}_{16} \mathrm{H}_{14} \mathrm{MoN}_{4} \mathrm{O}_{5}$ : C 43.13 (41.98); H 3.02 (2.36); N 11.74 (10.14). Selected IR data $\left(\mathrm{cm}^{-1}\right)$ : 3341, $3207\left(\mathrm{NH}_{2}\right), 1551$ ( $\mathrm{C}=\mathrm{N}$ imine), 1232 (C-Ophenolate), 902, $925\left(\mathrm{MoO}_{2}{ }^{2+}\right), 870$ ( $\left.\mathrm{Mo}=\mathrm{O} \cdots \mathrm{Mo}\right)$. TG: calcd. for $\mathrm{MoO}_{3}, 34.47 \%$, found $35.27 \%$, for $\mathrm{MeCN}$ calcd. $4.91 \%$, found $4.15 \%$; complex decomposition $301-469{ }^{\circ} \mathrm{C}$.

Complex 4, $\left[\mathrm{MoO}_{2}\left(\mathrm{~L}^{4}\right)\right] 2$. Dark red product. Yield: $0.532 \mathrm{~g}(89 \%)$. Mass fraction of elements, w / \%, calculated (experimental) for $\mathrm{C}_{28} \mathrm{H}_{22} \mathrm{Mo}_{2} \mathrm{~N}_{6} \mathrm{O}_{10}$ : C 42,33 $(41,18) ; \mathrm{H} 2,79(1,89) ; \mathrm{N} 10,58$ $(9,78)$. Selected IR data $\left(\mathrm{cm}^{-1}\right)$ : 3330, $3267\left(\mathrm{NH}_{2}\right), 1603$ (C=Nimine), 1230 (C-Ophenolate), 947 (MoN), 919, 872, $\left(\mathrm{MoO}_{2}{ }^{2+}\right)$. TG: calcd. for $\mathrm{MoO}_{3}, 36.24 \%$, found $38.69 \%$. 
Polynuclear complex $4^{\star \star}\left[\mathrm{MoO}_{2}\left(\mathrm{~L}^{4}\right)\right] n$ obtained by solvothermal procedure from methanol. Reaction time: $4 \mathrm{~h}$, reaction temperature: $110^{\circ} \mathrm{C}$. Dark red product. Selected IR data $\left(\mathrm{cm}^{-1}\right)$ : 3333, $3270\left(\mathrm{NH}_{2}\right), 1603$ (C=Nimine), 1232 (C-Ophenolate), 918, 875, $\left(\mathrm{MoO}_{2}{ }^{2+}\right)$. TG: calcd. for $\mathrm{MoO}_{3}$, $36.24 \%$, found $36.08 \%$; complex decomposition $322-489{ }^{\circ} \mathrm{C}$.

Mononuclear complexes $\left[\mathrm{MoO}_{2}(\mathrm{~L})(\mathrm{MeOH})\right]$ General procedure: $0.083 \mathrm{~g}(0.306 \mathrm{mmol})$ of the $\mathrm{H}_{2} \mathrm{~L}^{1-4}$ ligand was dissolved in $50 \mathrm{~mL}$ of methanol and refluxed for 1 hour after which $0.1 \mathrm{~g}(0.307$ $\mathrm{mmol})$ of $\left[\mathrm{MoO}_{2}(\mathrm{acac})_{2}\right]$ was added. The yellow reaction mixture was cooled to room temperature and then stored at $-8^{\circ} \mathrm{C}$ for one month. The obtained products were filtered off.

Complex 1a, $\left[\mathrm{MoO}_{2}\left(\mathrm{~L}^{1}\right)(\mathrm{MeOH})\right]$ Orange product. Yield: $0.015 \mathrm{~g}(12.8 \%)$. Mass fraction of elements, w/\%, calculated (experimental) for $\mathrm{C}_{15} \mathrm{H}_{15} \mathrm{MoN}_{3} \mathrm{O}_{6}$, are: $\mathrm{C}, 41.97(40.88) ; \mathrm{H}, 3.52$ (3.23); N, 9.79 (9.63). Selected IR data $\left(\mathrm{cm}^{-1}\right)$ : 3331, $3256(\mathrm{NH} 2), 1613\left(\mathrm{C}=\mathrm{N}_{\text {imine }}\right), 1574(\mathrm{C}=\mathrm{C})$, $1327(\mathrm{C}-\mathrm{O}), 1240$ (C-Ophenolate), $916\left(\mathrm{MoO}_{2}{ }^{2+}\right), 893\left(\mathrm{MoO}_{2}{ }^{2+}\right)$. TG: calcd. for $\mathrm{MoO}_{3}, 33.54 \%$, found $33.54 \%$, for $\mathrm{MeOH}$ calcd. $7.46 \%$, found $7.46 \%$.

Complex 2a, $\left[\mathrm{MoO}_{2}\left(\mathrm{~L}^{2}\right)(\mathrm{MeOH})\right] \cdot \mathrm{MeOH}$, Orange product. Yield: $0.075 \mathrm{~g}(61.5 \%)$. Mass fraction of elements, w/ \%, calculated (experimental) for $\mathrm{C}_{16} \mathrm{H}_{21} \mathrm{MoN}_{3} \mathrm{O}$, are: $\mathrm{C}, 41.48$ (40.89); $\mathrm{H}, 4.57$ (3.78); N, 9.07 (8.15). Selected IR data $\left(\mathrm{cm}^{-1}\right)$ : 3326 (NH2), 1602 (C=Nimine), $1568(\mathrm{C}=\mathrm{C}), 1347$ (C-O), 1261 (C-Ophenolate), 938, $919\left(\mathrm{MoO}_{2}{ }^{2+}\right), 891\left(\mathrm{MoO}_{2}{ }^{2+}\right)$. TG: calcd. for $\mathrm{MoO}_{3}, 30.95 \%$, found $33.33 \%$, for $\mathrm{MeOH}$ calcd. $13.76 \%$, found $12.97 \%$.

Complex 3a, $\left[\mathrm{MoO}_{2}\left(\mathrm{~L}^{3}\right)(\mathrm{MeOH})\right]$, Orange product. Yield: $0.043 \mathrm{~g}(52 \%)$. Mass fraction of elements, $\mathrm{w} / \%$, calculated (experimental) for $\mathrm{C}_{15} \mathrm{H}_{15} \mathrm{MoN}_{3} \mathrm{O}_{6}$ are: $\mathrm{C} 41,97(41,13) ; \mathrm{H} 3,52$ $(3,11)$; N 9,79 (9,01). Selected IR data $\left(\mathrm{cm}^{-1}\right)$ : 1595 (C=Nimine), 1227 (C-Ophenolate), $1125(\mathrm{MeOH})$, 930, $904\left(\mathrm{MoO}_{2}{ }^{2+}\right)$, TG: calcd. for $\mathrm{MoO}_{3}, 33.54 \%$, found $34.33 \%$, for $\mathrm{MeOH}$ calcd. $7.46 \%$, found $7.12 \%$.

Complex 4a, $\left[\mathrm{MoO}_{2}\left(\mathrm{~L}^{4}\right)(\mathrm{MeOH})\right]$, Orange product. Yield: $0.025 \mathrm{~g}(19 \%)$. Mass fraction of elements, w / \%, calculated (experimental) for $\mathrm{C}_{15} \mathrm{H}_{15} \mathrm{MoN}_{3} \mathrm{O}_{6}$ are: $3365,3465\left(\mathrm{NH}_{2}\right), \mathrm{C} 41,97$ $(41,02)$; H 3,52 (2,87); N 9,79 (8,31). Selected IR data (cm-1): 1598 (C=Nimine), 1232 (COphenolate), $1129(\mathrm{MeOH}), 928,897\left(\mathrm{MoO}_{2}{ }^{2+}\right)$, TG: calcd. for $\mathrm{MoO}_{3}, 33.54 \%$, found $35.76 \%$, for $\mathrm{MeOH}$ calcd. $7.46 \%$, found $7.66 \%$.

\subsection{Catalysis: General procedure for the epoxidation of olefins}

$20 \mathrm{mmol}$ of olefin (2.204 g of cis-cyclooctene or $2.244 \mathrm{~g}$ of oct-1-ene) and $0.1 \mathrm{~g}$ of acetophenone were stirred together. $0.25 \mathrm{~mol} \%$ of $\mathrm{Mo}(\mathrm{VI})$ (pre)catalyst was added in the mixture i.e. 0.05 $\mathrm{mmol}$ of the dinuclear and mononuclear complex. The mixture was stirred and heated up to $80^{\circ} \mathrm{C}$ before adding $40 \mathrm{mmol}$ of oxidant (protocols A-C). Protocol A: $5.48 \mathrm{~mL}$ of aqueous TBHP, protocol B: $3.48 \mathrm{~mL}$ of $\mathrm{H}_{2} \mathrm{O}_{2}$ and protocol C: $7.27 \mathrm{~mL}$ of TBHP in decane. All reactions were monitored for 5 hours. At defined times $0,20,50,90,150,300$ minutes, aliquots ( $\approx 0.1 \mathrm{~mL})$ of the organic phase were taken from the reaction mixture and diluted with $\mathrm{Et}_{2} \mathrm{O}$. Catalytic reactions were followed along the time through GC measurements. In the reaction in which 
TBHP in decane was used as the oxidant, defined times for taking aliquots for the analysis were $0,2.5,5,10,15,20,30$ minutes.

\section{Acknowledgements}

This work has been supported in part by Croatian Science Foundation, Croatia under the project (IP-2016-06-4221). We acknowledge the support of project CluK co-financed by the Croatian Government and the European Union through the European Regional Development FundCompetitiveness and Cohesion Operational Programme (Grant KK.01.1.1.02.0016.). LCC CNRS and IUT Chem Dept are acknowledged for equipment for the catalysis experiments. LCC and Calmip are acknowledged for the facilities in terms of calculation time. Erasmus+ program supported the internship of A. Bafti and M. Razum. Mirta Rubčić is acknowledged for valuable advice and suggestions during the writing process.

\section{Conflict of interest}

The authors declare no conflict of interest.

\section{References}

[1] R. N. McDonald, R. N. Steppel, J. E. Dorsey, Org. Synth. 50 (1970) 15-18. https://doi.org/10.15227/orgsyn.050.0015.

[2] E. Rose, B. Andrioletti, S. Zrig, M. Quelquejeu-Etheve, Chem. Soc. Rev. 34 (2005) 573-583. https://doi.org/10.1039/B405679P.

[3] J. Pisk, D. Agustin, V. Vrdoljak, Catal. Commun. 142 (2020) 106027. doi:10.1016/j.catcom.2020.106027.

[4] K. Dallmann, R. Buffon, W. Loh, J. Mol. Catal. A-Chem. 178 (2002) 43-46. https://doi.org/10.1016/S1381-1169(01)00293-X.

[5] R. Martos Calvente, J. M. Campos-Martin, J. L. G. Fierro, Catal. Commun. 3 (2002) 247 251. https://doi.org/10.1016/S1566-7367(02)00106-1.

[6] J. Pisk, D. Agustin, V. Vrdoljak, R. Poli, Adv. Synth. Catal. 353 (2011) 2910-2914. https://doi.org/10.1002/adsc.201100439.

[7] J. Morlot, N. Uyttebroeck, D. Agustin, R. Poli, ChemCatChem 5 (2013) 601 - 611. https://doi.org/10.1002/cctc.201200068.

[8] J. Pisk, M. Rubčić, D. Kuzman, M. Cindrić, D. Agustin, V. Vrdoljak, New J. Chem. 43 (2019) 5531-5542. https://doi.org/10.1039/C9NJ00229D.

[9] D. Cvijanović, J. Pisk, G. Pavlović, D. Šišak-Jung, D. Matković-Čalogović, M. Cindrić, D. Agustin, V, Vrdoljak, New. J. Chem. 43 (2019) 1791-1802. https://doi.org/10.1039/C8NJ04074E.

[10] M. M. Javadi, M. Moghadam, I. Mohammadpoor-Baltork, S. Tangestaninejad, V. Mirkhani, H. Kargar, M. Nawaz Tahir, Polyhedron 72 (2014) 19-26. https://doi.org/10.1016/.j.poly.2014.01.004. 
[11] M. Abrantes, A. M. Santos, J. Mink, F. E. Kühn, C.C. Romão, Organometallics 22 (2003) 2112. https://doi.org/10.1021/om0300023.

[12] J. M. Mitchell, N. S. Finney, J. Am. Chem. Soc. 123 (2001) 862-869. https://doi.org/10.1021/ja002697u.

[13] A. Rezaeifard, I. Sheikhshoaie, N. Monadi, H. Stoeckli-Evans, Eur. J. Inorg. Chem. (2010) 799-806. https://doi.org/10.1002/ejic.200900814.

[14] H. Mimoun, I. Seree de Roch, L. Sajus, Tetrahedron 26 (1970) 37-50. https://doi.org/10.1016/0040-4020(70)85005-0.

[15] H. Mimoun, Angew. Chem. Int. Ed. Engl. 21 (1982) 734-750. https://doi.org/10.1002/anie.198207341.

[16] K. B. Sharpless, J. M. Townsen, D. R. Williams, J. Am. Chem. Soc. 94 (1972) 295-296. https://doi.org/10.1021/ja00756a062.

[17] K. A. Jørgensen, R. Hoffmann, Acta Chem. Scand., Ser. B 40 (1986) 411-419.

[18] P. Macchi, A. J. Schultz, F. K. Larsen, B. B. Iversen, J. Phys.Chem. A 105 (2001) 92319241. https://doi.org/10.1021/ip011328x

[19] J. Pisk, I. Đilovic, T. Hrenar, D. Cvijanovic, G. Pavlović, V. Vrdoljak, RSC Advances 10(63) (2020) 38566-38577. https://doi.org/10.1039/D0RA06845D.

[20] J. R. Sohn, H. D. Park, D. D. Lee, Appl. Surf. Sci. 161 (2000) 78-85. https://doi.org/10.1016/S0169-4332(00)00135-5.

[21] M. Cindrić, V. Vrdoljak, N. Strukan, B. Kamenar, Polyhedron 24 (2005) 369-376. https://doi.org/10.1016/i.poly.2004.12.007.

[22] S. Sinha, M. Chakraborty, N. R. Pramanik, T. K. Raychaudhuri, T. K. Mondal, D. Sarkar, M. G. B. Drew, S. Ghosh, S. S. Mandal, Polyhedron 55 (2013) 192-200. https://doi.org/10.1016/j.poly.2013.03.022.

[23] W. Wang, J.-C. Daran, R. Poli, D. Agustin, J. Mol. Catal. A: Chem. 416 (2016) 117-126. https://doi.org/10.1016/j.molcata.2016.02.021.

[24] J. Pisk, M. Rubčić, D. Kuzman, M. Cindrić, D. Agustin, V. Vrdoljak, New J. Chem. 43 (2019) 5531-5542. https://doi.org/10.1039/C9NJ00229D.

[25] M. Cindrić, G. Pavlović, R. Katava, D. Agustin, New J. Chem. 41 (2017) 594-602. https://doi.org/10.1039/C6NJ03174A.

[26] W. Wang, T. Guerrero, S. R. Merecias, H. García-Ortega, R. Santillan, J.-C. Daran, N. Farfán, D. Agustin, R. Poli, Inorg. Chim. Acta 431 (2015) 176-183. https://doi.org/10.1016/.ica.2014.12.022.

[27] L. F. Veiros, C. A. Gamelas, M. J. Calhorda, Carlos C. Romão, Organometallics 30 (2011) 1454-1465. https://doi.org/10.1021/om101044f

[28] D. V. Deubel, J. Sundermeyer, G. Frenking, Inorg. Chem. (2000) 39, 2314-2320. https://doi.org/10.1021/ic000204g

[29] I. V. Yudanov, C. Di Valentin, P. Gisdakis, N. Rosch, J. Mol. Catal. A: Chem. (2000) 158, 189-197. https://doi.org/10.1016/S1381-1169(00)00065-0

[30] L. F. Veiros, A. Prazeres, P. J. Costa, C. C. Romao, F. E. Kuhn, M. J. Calhorda, Dalton Trans., 2006, 1383-1389. https://doi.org/10.1039/B515484G

[31] A. Comas-Vives, A. Lledos, R. Poli, Chem. Eur. J. (2010) 16, 2147 - 2158. https://dx.doi.org/10.1002/chem.200902873 
[32] C. Di Valentin, P. Gisdakis, I. V. Yudanov, N. Rösch J. Org. Chem. (2000) 65, 2996-3004. https://doi.org/10.1021/j09916784

[33] M. Drees, S. A. Hauser, M. Cokoja, F. E. Kühn, J. Organomet. Chem. (2013) 748, 36-45. https://doi.org/10.1016/j.jorganchem.2013.05.004

[34] J. A. Brito, M. Gómez, G. Muller, H. Teruel, J. - C. Clinet, E. Duñach, M. A. Maestro, Eur. J. Inorg. Chem. 2004, 4278-4285. https://doi.org/10.1002/ejic.200400331.

[35] C. D. Valentin, P. Gisdakis, I. V. Yudanov, N. Rösch, J. Org. Chem. 65(10) (2000) 29963004. https://doi.org/10.1021/j09916784.

[36] W. R. Thiel, M. Barz, H. Glas, A.-K. Pleier in Peroxide Chemistry (2005) 433-453.

[37] P. Gisdakis, I. V. Yudanov, Notker Rösch, Inorg. Chem, 2001, 40(15), 3755-3765. https://doi.org/10.1021/ic010201j.

[38] I. V. Yudanov, C. Di Valentin, P. Gisdakis, N. Rosch, J. Mol. Catal. A: Chem. 2000, 158, 189-197. https://doi.org/10.1016/S1381-1169(00)00065-0.

[39] S. A. Hauser, R. M. Reich, J. Mink, A. Pöthig, M. Cokoja, F. E. Kühn, Catal. Sci. Technol., 2015, 5, 2282-2289. https://doi.org/10.1039/C4CY01604A.

[40] E. Ishikawa, D. Kihara, Y. Togawa, C. Ookawa, Eur. J. Inorg. Chem. 2019, 402-409. https://doi.org/10.1002/ejic.201800869.

[41] C. Müller, N. Grover, M. Cokoja, F. E. Kühn, Adv. Inorg. Chem. 65 (2013) 33-83. https://doi.org/10.1016/B978-0-12-404582-8.00002-X.

[42] D. V. Deubel, J. Sundermeyer, G. Frenking, Eur. J. Inorg. Chem. (2001) 1819-1827. https://doi.org/10.1002/1099-0682(200107)2001:7<1819::AID-EJIC1819>3.0.CO;2-K.

[43] H. B. Kagan, H. Mimoun, C. Mark, V. Schurig, Angew. Chem. Int. Ed. Engl. 18(6) (1979) 485-486. https://doi.org/10.1002/anie.197904851.

[44] M. José Calhorda, P. J. Costa, Curr. Org. Chem. 16 (2012) 65-72. https://doi.org/10.2174/138527212798993095.

[45] Rigaku Oxford Diffraction (2018). CrysAlisPro. Version 1.171.39.46e. Rigaku Oxford Diffraction, The Woodlands, Texas, USA

[46] G. M. Sheldrick, Acta Cryst. A71 (2015) 3-8. https://doi.org/10.1107/S2053273314026370.

[47] G. M. Sheldrick, Acta Cryst. C71, (2015) 3-8. https://doi.org/10.1107/S2053229614024218.

[48] O. V. Dolomanov, L. J. Bourhis, R. J. Gildea, J. A. K. Howard, H. Puschmann, J. Appl. Cryst. 42 (2009) 339-341. https://doi.org/10.1107/S0021889808042726.

[49] C. R. Groom, I. J. Bruno, M. P. Lightfoot, S. C. Ward, Acta Cryst. B72 (2016) 171. https://doi.org/10.1107/S2052520616003954.

[50] M. J. Frisch, G. W. Trucks, H. B. Schlegel, G. E. Scuseria, M. A. Robb, J. R. Cheeseman, G. Scalmani, V. Barone, B. Mennucci, G. A. Petersson, H. Nakatsuji, M. Caricato, X. Li, H. P. Hratchian, A. F. Izmaylov, J. Bloino, G. Zheng, J. L. Sonnenberg, M. Hada, M. Ehara, K. Toyota, R. Fukuda, J. Hasegawa, M. Ishida, T. Nakajima, Y. Honda, O. Kitao, H. Nakai, T. Vreven, J. A. Montgomery Jr., J. E. Peralta, F. Ogliaro, M. Bearpark, J. J. Heyd, E. Brothers, K. N. Kudin, V. N. Staroverov, T. Keith, R. Kobayashi, J. Normand, K. Raghavachari, A. Rendell, J. C. Burant, S. S. Iyengar, J. Tomasi, M. Cossi, N. Rega, J.M. Millam, M. Klene, J. E. Knox, J. B. Cross, V. Bakken, C. Adamo, J. Jaramillo, R. Gomperts, R. E. Stratmann, O. Yazyev, A. J. Austin, R. Cammi, C. Pomelli, J. W. Ochterski, R. L. Martin, K. Morokuma, V. G. Zakrzewski, G. A. Voth, P. Salvador, J. J. Dannenberg, S. Dapprich, A. D. Daniels, O. 
Farkas, J. B. Foresman, J. V. Ortiz, J. Cioslowski, D.J. Fox. Gaussian, Inc, Wallingford CT (2013)

[51] D. Becke, J.Chem. Phys. 98 (1993) 5648-5652. https://doi.org/10.1063/1.464913.

[52] C. T. Lee, W. T. Yang, R. G. Parr, Phys. Rev. B: Condens. Matter Mater. Phys. 37 (1988) 785-789. https://doi.org/10.1103/PhysRevB.37.785.

[53] B. Miehlich, A. Savin, H. Stoll, H. Preuss, Chem. Phys. Lett. 157 (1989) 200-206. https://doi.org/10.1016/0009-2614(89)87234-3.

[54] R. Ditchfield, W.J. Hehre, J.A. Pople, J. Chem. Phys. 54 (1971) 724-728. https://doi.org/10.1063/1.1674902.

[55] W. Hehre, R. Ditchfield, J. Pople, J. Chem. Phys. 56 (1972) 2257-2261. https://doi.org/10.1063/1.1677527.

[56] P. C. Hariharan, J.A. Pople, Theor. Chim. Acta 28 (1973) 213-222. https://doi.org/10.1007/BF00533485.

[57] P. C. Hariharan, J.A. Pople, Mol. Phys. 27 (1974) 209-214. https://doi.org/10.1080/00268977400100171.

[58] W. J. Stevens, H. Basc, M. Krauss, J. Chem. Phys. 81 (1984) 6026-6033. https://doi.org/10.1063/1.447604.

[59] W. J. Stevens, M. Krauss, H. Basch, P. G. Jasien, Can. J. Chem. 70 (1992) 612-630. https://doi.org/10.1139/v92-085.

[60] J. Tomasi, B. Mennucci, R. Cammi, Chem. Rev. 105 (2005) 2999-3094. https://doi.org/10.1021/cr9904009. 


\section{Graphical abstract}

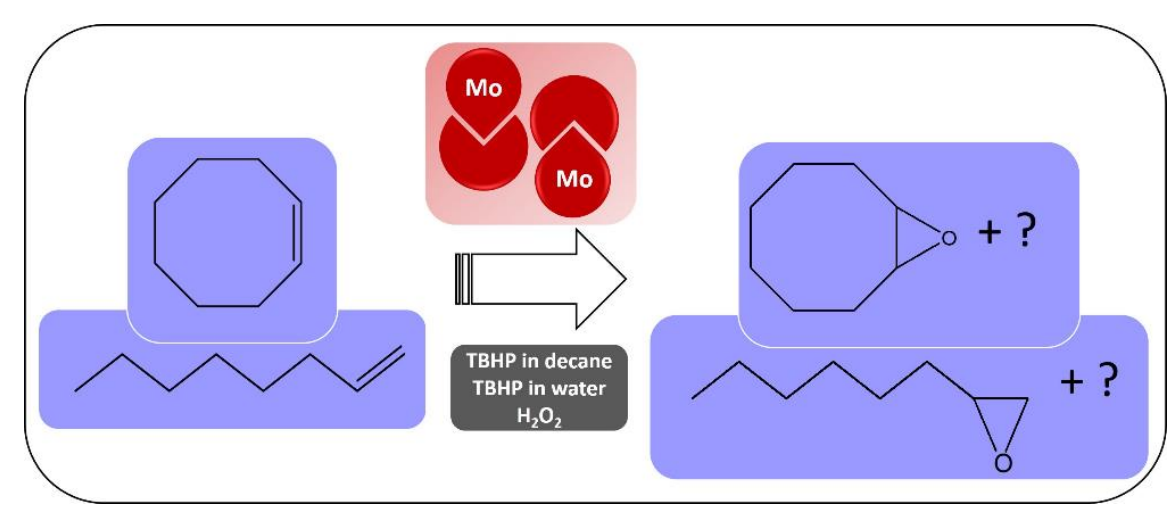

